\title{
Research Paper \\ Localization of Indicators of Social Capital in Rural Areas of Iran
}

\author{
*Samira Mahmoodi ${ }^{1}$, Abdolreza Rokneddin EfTekhari ${ }^{2}$, Gholamreza Ghaffari ${ }^{3}$
}

1. Assistant Professor, Department of Geography and Urban Planning, Faculty of Literature and Humanities, University of Guilan, Rasht, Iran. 2. Professor, Department of Physical Geography, School of Humanities, Tarbiat Modares University, Tehran, Iran.

3. Associate Professor, Department of Sociology, Faculty of Social Sciences, University of Tehran, Tehran, Iran.

Received: 15 Aug. 2016 Accepted:17 Nov. 2016

Keywords:

Social capital, Rural sustainable development, Localization of indicators, Rural areas, Iran ditation: Mahmoodi, S., Rokneddin Eftekhari, A., \& Ghaffari, Gh. (2017). Localization of Indicators of Social Capital in Rural Areas of Iran (Persian)]. Journal of Rural Research, 7(4), 618-643. http://dx.doi.org/10.21859/jjr-07043

\begin{abstract}
Given the potential role of social capital in reducing poverty and enhancing sustainable development, there have been many attempts to design assessment tools for it. Social capital is a complex concept with multiple measures. This feature requires a set of indicators to compare its different aspects. In this context, the question is what the localization process indicators of social capital are in rural areas of Iran. The scientific solution to the problem needs an appropriate set of indicators to measure social capital in rural areas of Iran. The present paper used cross-surveys and feedback from experts, and academics. We also used the Delphi method to provide appropriate indicators and criteria which have been localized. For data analysis, statistical methods such as mean and variance were calculated using Excel and SPSS. Based on the findings in the total number of 9 components, 18 indexes and 53 indicators were selected that are compatible with rural areas of Iran. Moreover, by localization of social capital indicators in sustainable rural development, it is possible to select the indicators that are consistent and comply with Iranian villages, operational aspects, and applicable to these components. Also indexes and indicators in sustainable rural development programs will be considered.
\end{abstract}

\section{Extended Abstract}

\section{Introduction}

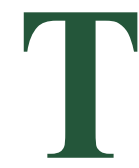

he historical experience of developed countries made it clear that rural sustainable development is a necessary foundation for national development and should be a priority in the development agenda. The concept of sustainable development as development is underway to develop a variety of ways to express concepts as varied as the landscapes, exchanging values and moral development, social reorganization, transformation process towards a better future, environmental quality environment, empowering the people, creating new capacity, respect for indigenous knowledge, awareness-raising and information, the satisfaction of getting people into their lives and freedom of choice and equality in access to opportunities is taken in to consideration that all of which somehow explains the central idea of sustainable development that "meets the needs of the present generation to consider the needs of future generations". According to literature review, sustainable development became a serious issue in the first decade of the 20th century and in 
the following decades, a movement started to determine its indicators. Initially economic indicators such as GDP and GNP became common as the overall indicators of a nation well-being.

During the $60 \mathrm{~s}$ and $70 \mathrm{~s}$, some researchers protested to the criteria and methods, so that the social indicators were also appeared in the spotlight. In this regard, with the introduction of the collective investment in development, another type of capital was introduced as "social capital." In many studies, including sustainable development, rural development has been mentioned as a fundamental challenge, and scientists and planners were attracted to it more and more. In this regard, the World Bank, which allocated a large part of its activities to investigate and develop studies on the underdeveloped countries, assigned a separate part to the relationship between social capital and development of the countries. With regard to theoretical research, a lot of projects and studies have done on criteria and influence of social capital, including the definition and localization of the social capital, operationalization of the concept in different countries and solutions to development. Since the social capital, like other social phenomena arises in the historical and social context, application of measures of social capital outside of a particular cultures, institutional environment and historical context and power structures is one of the major problems and challenges in the field. In order to solve this problem, various approaches have been proposed by researchers.

Rose (1999) used three theoretical approaches for the analysis of social capital and conceptually divided them into three categories. First and important category is "theoretical position," in which social capital has been defined based on position and tool, i.e., this type of social capital is different from person to person and from one situation to another one. The second category is known as "psychosocial approach" and implies that social capital is a set of beliefs and cultural norms. Finally, the third category, "cultural theory," which considers culture as a source of trust and cooperation. In fact, according to this theory, social capital among individuals belonging to similar culture (society), as well as adapts is homogeneous from situation to another. Thus, it is essential that social capital is identified for a particular culture such as a country or a particular geographical area. So in order to check the current status of rural areas of Iran in terms of social capital and due to its remarkable impact on rural sustainable development, it is essential to define social capital in sustainable rural development and identify its indicators. Scientific and more accurate assessment should be conducted on the status of the social capital of rural areas. So in this paper, the above objectives are pursued by relying on "localization approach." In this context the question of how to do the localization process indicators of social capital in rural areas of Iran? and what are the most important indicators of social capital?

\section{Methodology}

To answer this question in a scientific way and create an appropriate set of indicators to measure social capital in rural areas of Iran, the present article by using descriptiveanalytical method; survey research; and consulting with experts, academics, and field specialists (including 15 professors, researchers, and managers) through Delphi method has attempted to provide appropriate and localized indicators. Also, for data analysis, statistical indexes such as mean and variance were calculated by Excel and SPSS.

\section{Results}

Based on the findings, a total number of 9 components, 18 indexes, and 53 indicators were selected that are compatible with the rural areas of Iran. Selected indicators are mental participation, physical participation, formal participation, membership in government networks and departments, membership in private network and groups, insurance services, security services in rural areas, physical security, personal knowledge, using the experiences of others, commitments and agreements, values and attitudes, interpersonal trust, generalized trust, institutional trust, interaction and conflict, relationships within the group and between groups, and out of group relations

\section{Discussion}

In order to select criteria of social capital, at first, social capital indicators were listed. In the second step, the primary indicators in rural sustainable development were screened and trimmed to the main indicator. Then, these indicators were analyzed based on their frequency in the different sources and the more frequent indicators were extracted. So based on survey studies and opinions of experts, the appropriate and localized social capital indicators in rural development areas were set and identified. In this context, based on the theoretical foundations and according to the results presented in Table 2, we excluded a lot of indicators and parameters which were repetitive or not compatible to the geographic conditions and sociocultural structure of Iran rural areas. Also some indicators due to their nature were replaced with similar compatible ones with the culture of Iran society and thus a localized measure of social capital for rural areas of Iran were found. 


\section{Conclusion}

Based on literature review, the localization process, which implies intellectual liberation and reevaluation of major Western development paradigms, has raised new forms of development that are based on knowledge and requirements of the third world people and generally is against outside professional views. Such a development essentially is neither against Western methods nor ignores the human experiences, but presents a more realistic view of development, reflecting the certain geographical and historical context. In fact, development opposes efforts to shape the people based on global models, which are kinds of racism and predefined standard, and reminds development authorities to consider the differences and learn from them. Moreover, through localization of social capital indicators in sustainable rural development, it is possible to not only select the indicators that are consistent and comply with the Iranian villages conditions, but also consider the operational aspects and application of these indicators in sustainable rural development programs. 


\title{
بومىسازى شاخصهاى سرمايه اجتماعى در مناطق روستايى ايران
}

\author{
•سميرا محمودى'، عبدالرضا ركنالدين افتخارى'، غلامرضا غفارى'

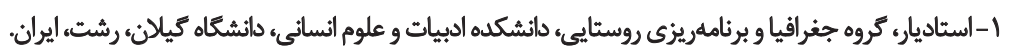

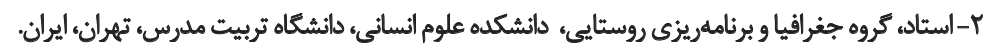

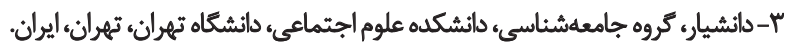

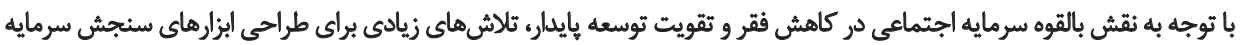

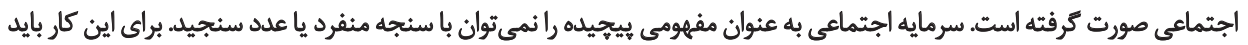

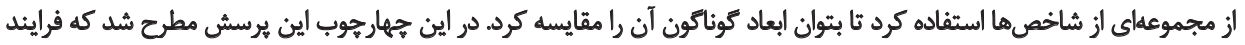

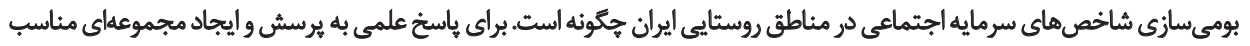

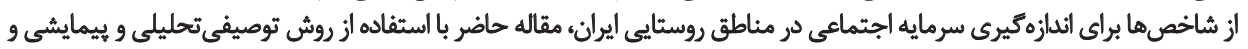

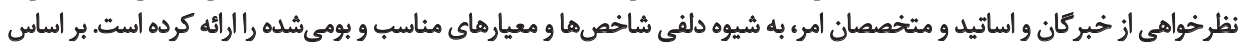

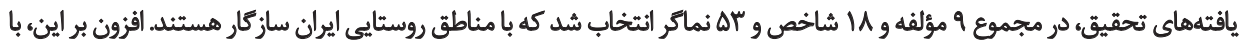

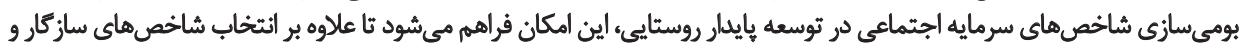

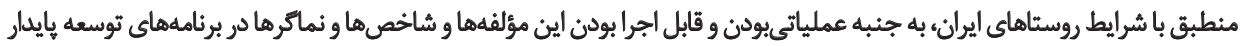

مفهوم توسعه بايدار همائند توسعه در جريان تحولى دواكي

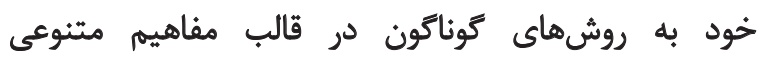

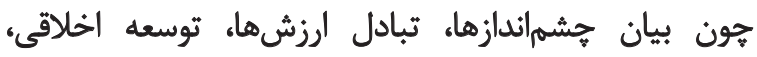

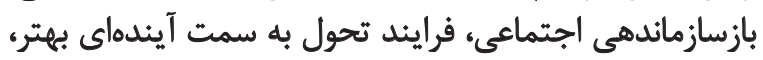

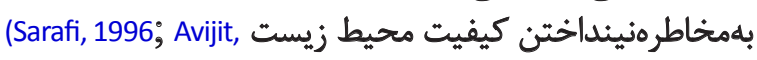
(1998; Schoeffel, Overton, \& Scheyvans, 2000)

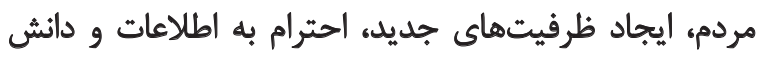

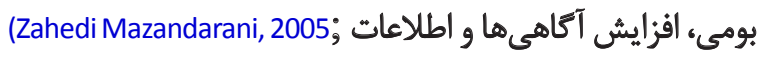

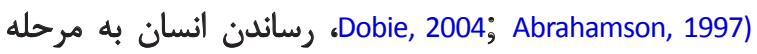

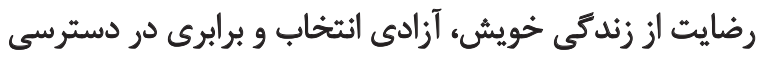

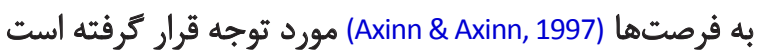
كه همكَى به نوعى تبيين كثنده ايده محورى توسعه تورايدار
توسعه با مبانى يُيجيدهاي كه با خود به همراه دارد

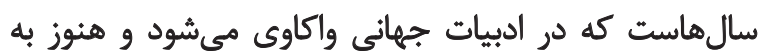

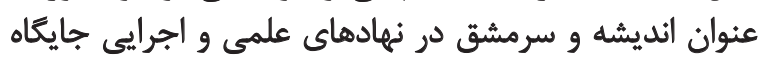

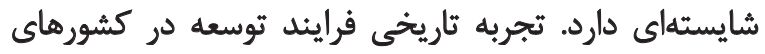

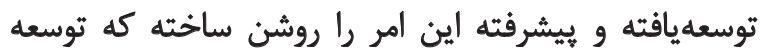

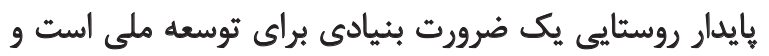

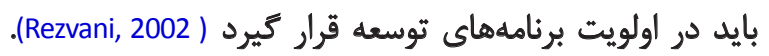

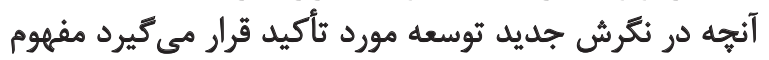

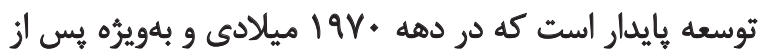

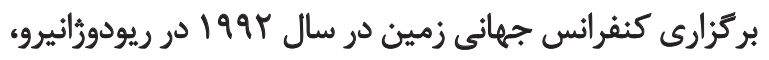

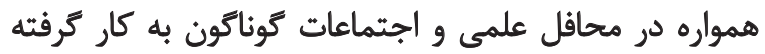

$$
\begin{aligned}
& \text { : نويسينده مسينول: }
\end{aligned}
$$

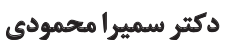

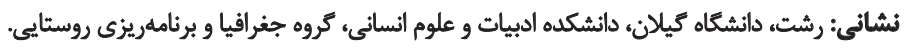

$$
\begin{aligned}
& \text { تلفن: } \\
& \text { smahmoodi@guilan.ac.ir : يست الكترونيكي }
\end{aligned}
$$




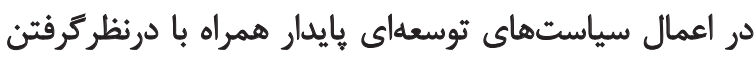

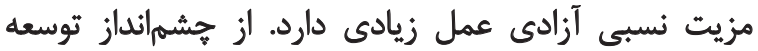

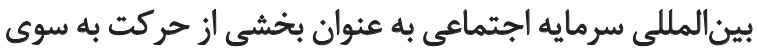

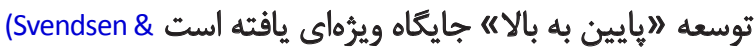
.Svendsen, 2000; Small, 2002 )

در اين جهارجوب سرمايه اجتماعى در مفهوم كلى در بسيارى

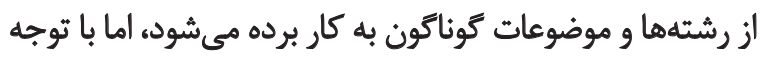

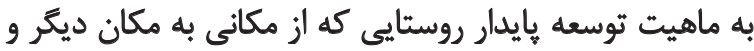

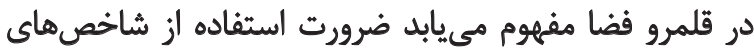

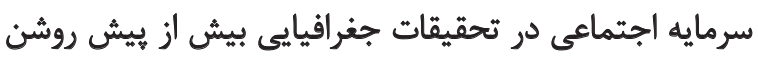

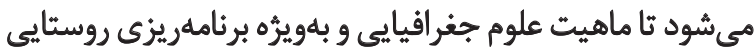

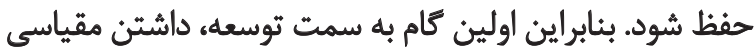

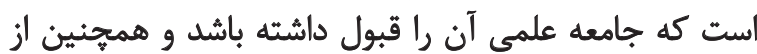

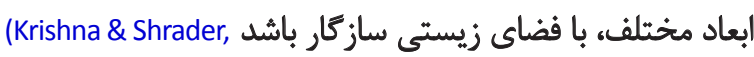

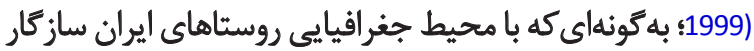

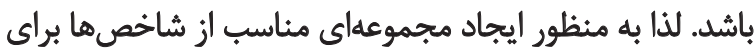

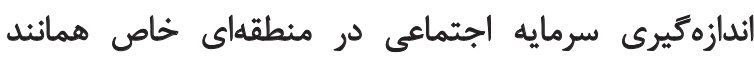

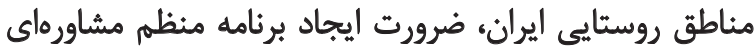

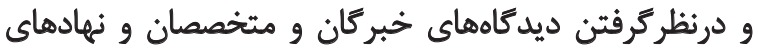
مختلف و ساير ذىنفعان مشاهده مى ديدان

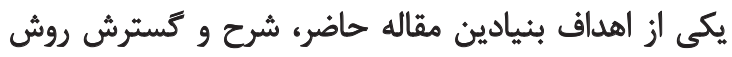

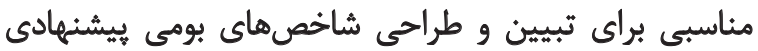

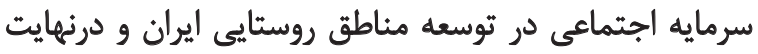

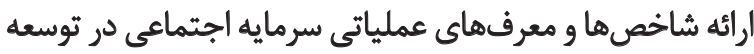

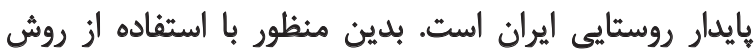

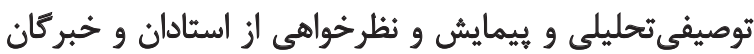

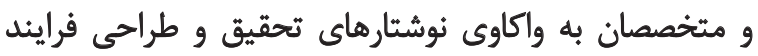

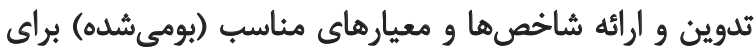

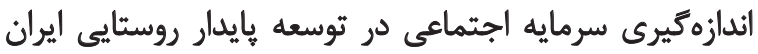

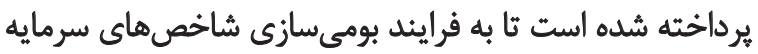

اجتماعى در مثاطق روستايى ايران باسخى علمى دايند داده شود.

$$
\text { T. مرورى بر ادبيات موضوع }
$$

$$
\text { سر مايه أجتماعي و ثوسعه روستائي }
$$

در دهه • 199 مفاهيم جديدى از توسعه جايكزين' مطرح

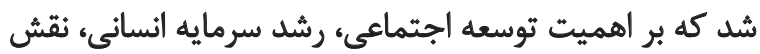

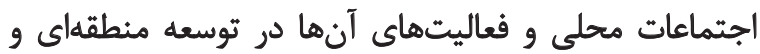

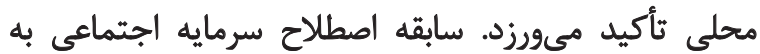

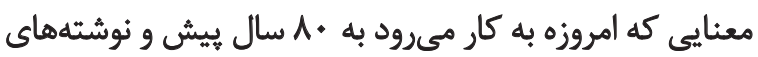

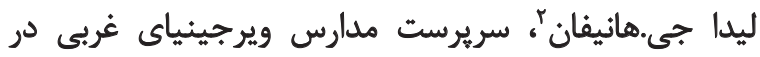

1. Alternative development

2. Lyda J. Hanifan
يعنى البرآورده ساختن نيازهاى نسل حاضر با درنظر آنرفتن نيازهاى نسل هاى آتى" است (Eftekhari \& Badri, 2012). در اين ههارجوب تفكر در انواع مختلف سرمايه اجتماع

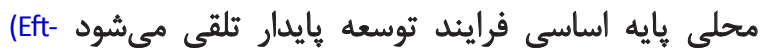
ekhari, Azimi Amoli, Pourtaheri, \& Ahmadipour, 2011)

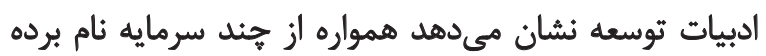

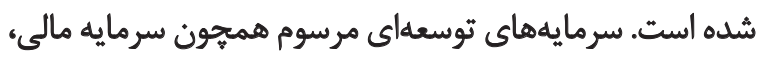

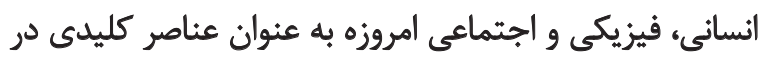

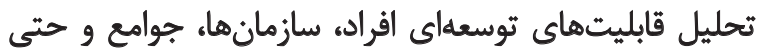

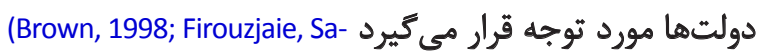

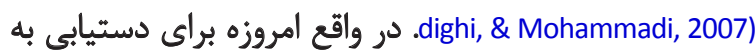

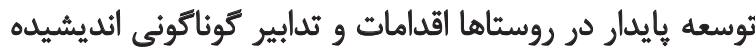

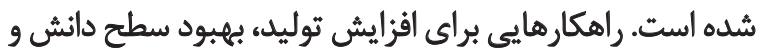

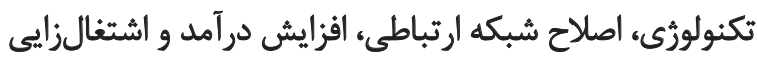

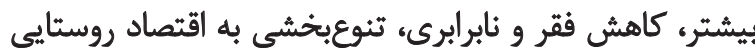

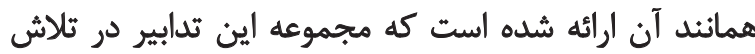

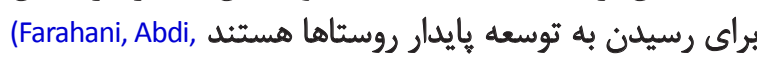
.\& Cheraghi, 2012; Azkia, \& Imani, 2008)

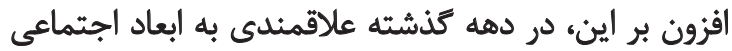

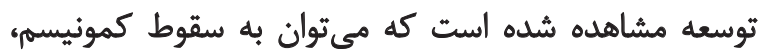

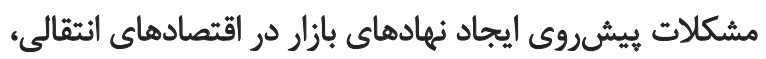

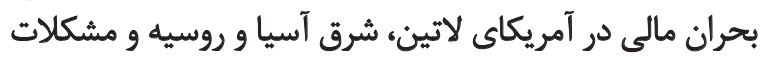

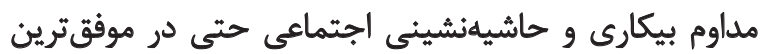

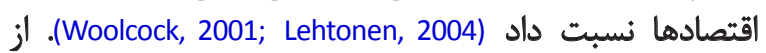

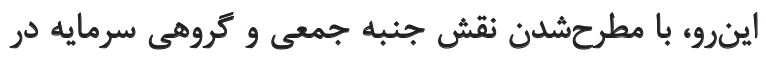

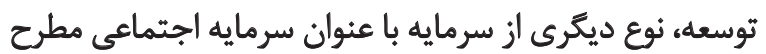

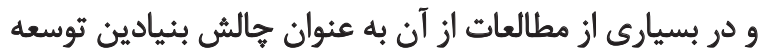

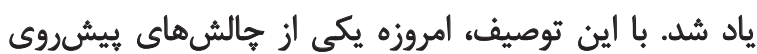

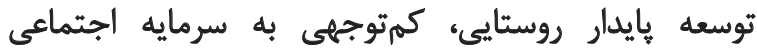

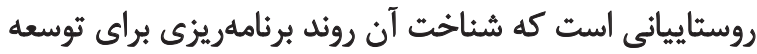

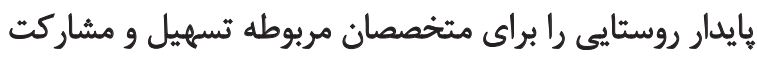

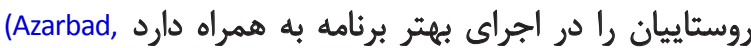

.Salmani, Motiee Langroudi, \& Eftekhari, 2010)

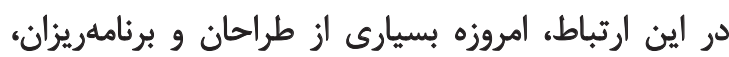

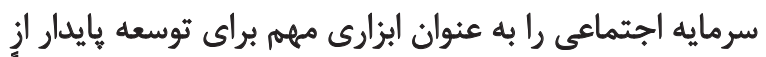

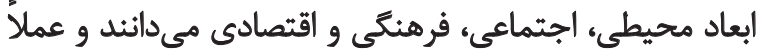

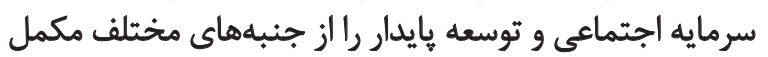
و مرتبط با يكديكر هي دانيد (Serageldin \& Grootaert, 2000).

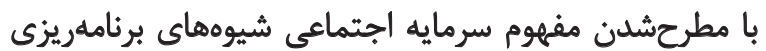

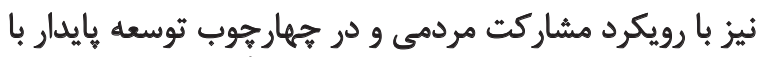

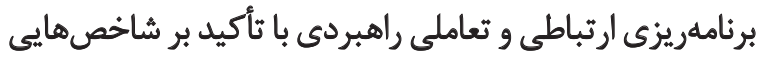

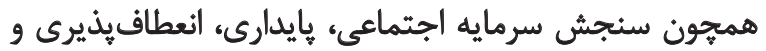

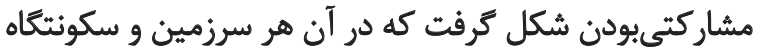


توسعه بسيار مؤثر است. سرمايه اجتماعى مى تواند مكمل

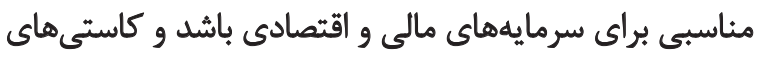

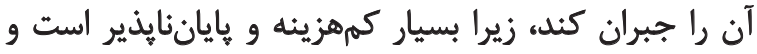

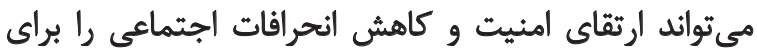

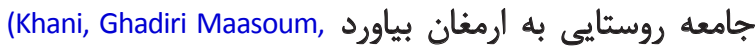
\&olkan, 2013)

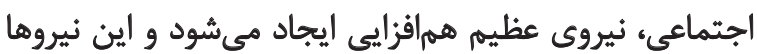

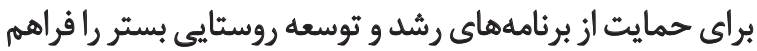

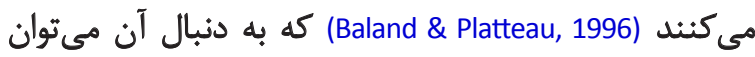

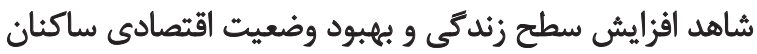

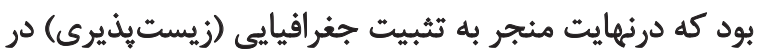
مناطق روستايى مىشود (Falk \& Kilpatrick, 2000).

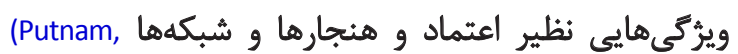

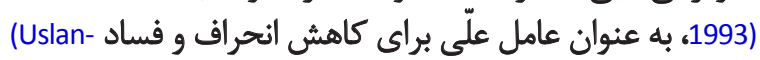
(White- er, 2001; Bjornskov \& Svendsen, 2003) (La Porta, وكمروايي خوب أصادي و ley, 2000; Zak \& Knack, 2001) نشان Lopez-de-Silanes, Schleifer \& Vishny, 1998; Knack, 2002) داده شده است (Bjornskov \& Svendsen, 2003). اصطلاح سرمايه

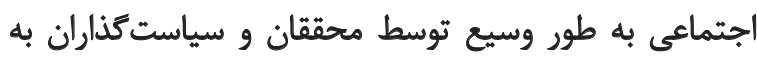

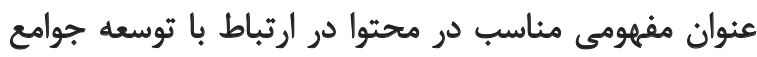
مورد توافق واقع شده است (Yokoyama \& Ishida, 2006).

مطالعات اخير روى سرمايه اجتماعى و توسعه بايدار

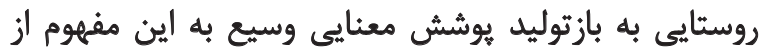

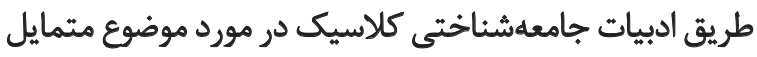

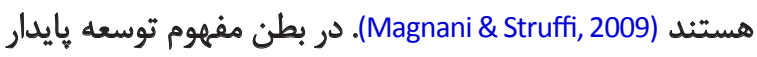

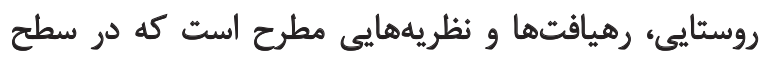

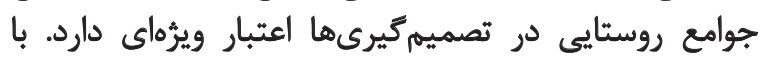

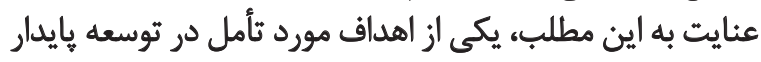

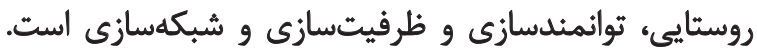

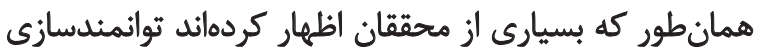

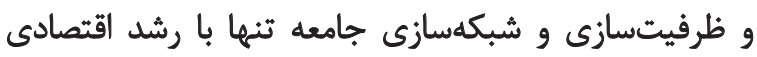

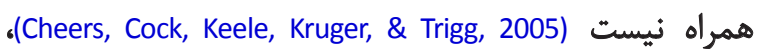

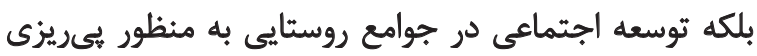

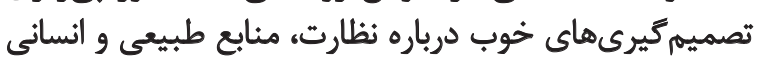

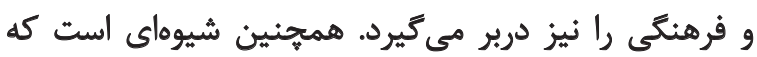

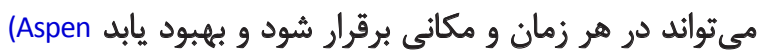

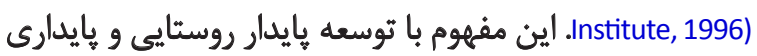

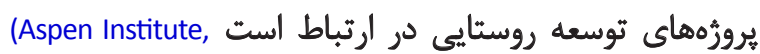
1996; Chambers, 1991; Flora et al., 1999; Schwarz et al., 2011; Merino, Carmenado, \& De Los 2012)

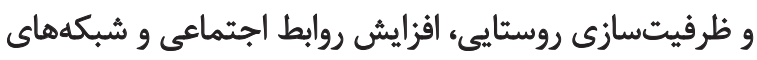
اجتماعى و سرمايه اجتماعى است (Putnam, 1993).

كريشنا از دو بُعد سرمايه اجتماعى نام مىبرد كه عبارتند ازئ

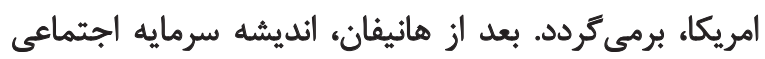

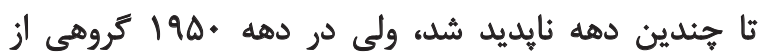

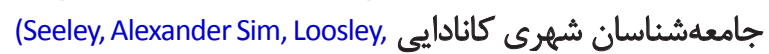
و و و در دهل .199esman, 1956)

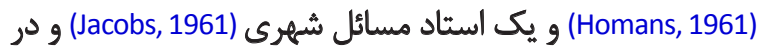

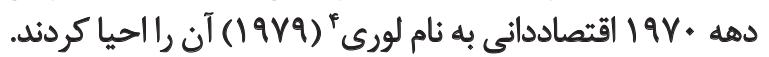

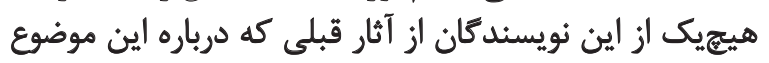

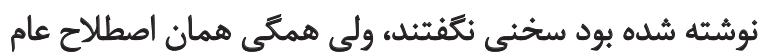

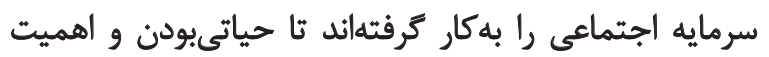
بيوندهاى اجتماعى را در آن خلاصه كنيند.

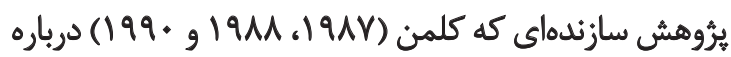

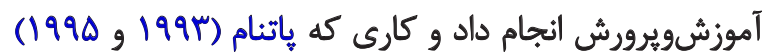

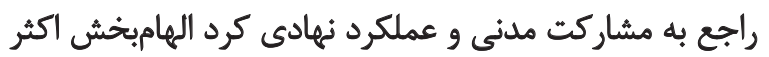

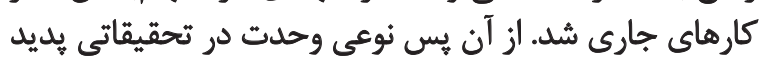

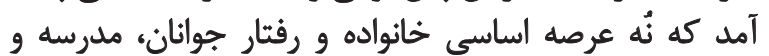

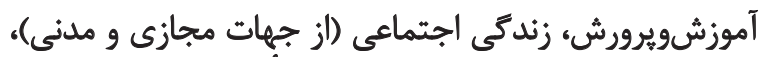

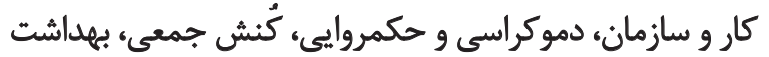

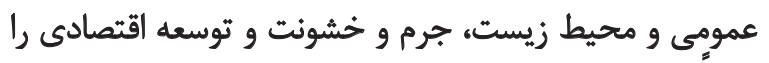
عملاً با يكديكَر ييوند مى وداد (Tajbakhsh, 2005).

رايجترين تعريف سرمايه اجتماعى به ويرّكى هاي سازمان

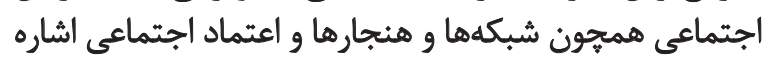

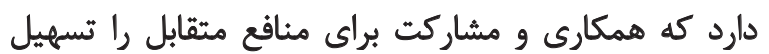

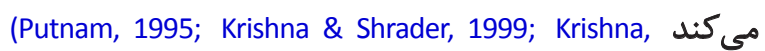

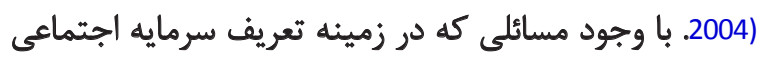

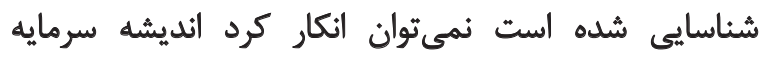

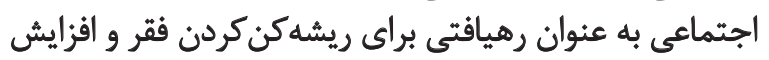

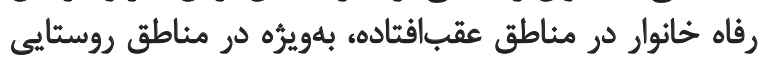

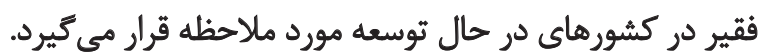

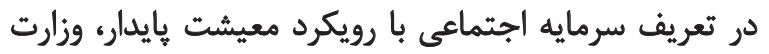

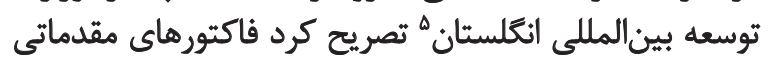

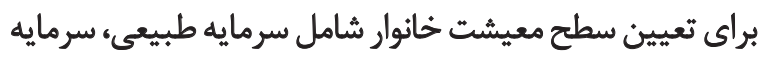

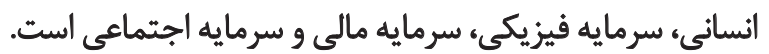

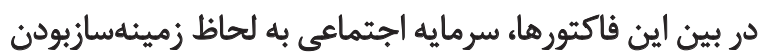

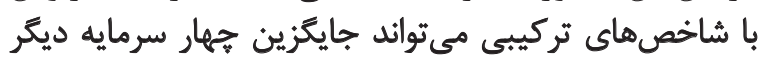
شود (DFID, 1999; Sakata, 2002).

از آنجا كه بيشتر مناطق روستايى بلويرٔه در جهان سوم

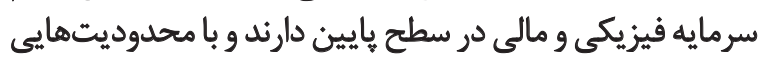

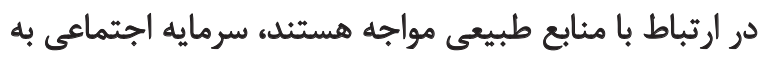

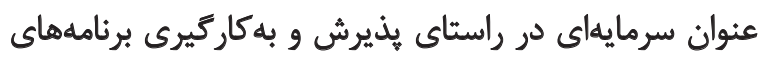

3. Exchange theorist

4. Loury

5.The Department for International Development of the United Kingdom 
فراوانى انجام داده است. ازجمله مطالعات مدنظر آنهاء تعريف

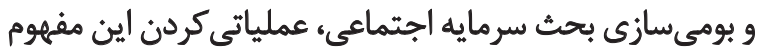

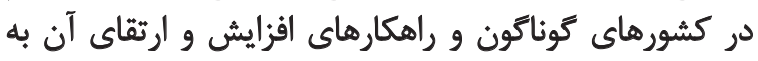
منظور توسعه است (Fathi, 2012). اوج تكامل شاخصسازى سرمايه اجتماعى را مىتوان تكامل

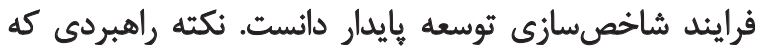

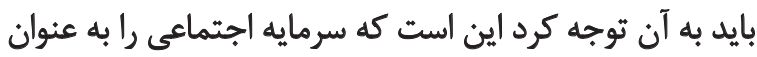

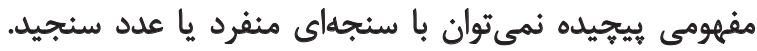

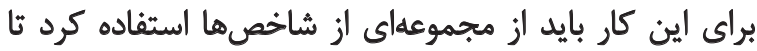

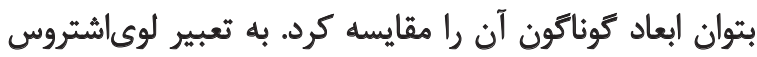

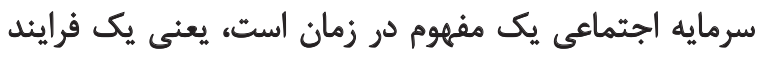

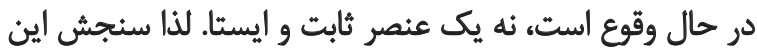

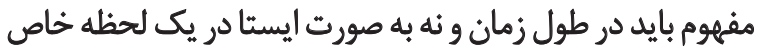

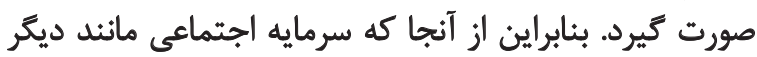

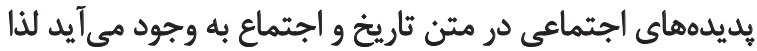

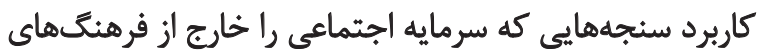

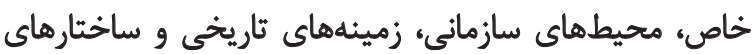

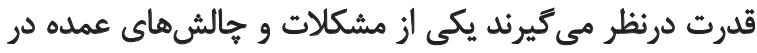
اين زميئه است (Fine \& Green, 2000; Healy, 2002).

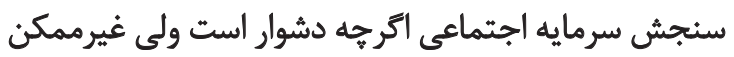

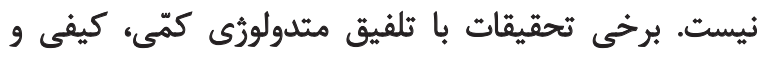

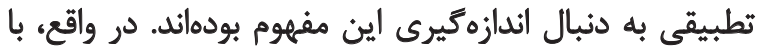

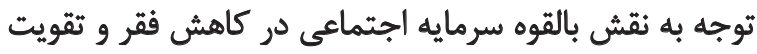

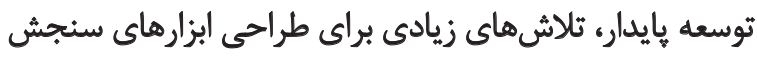

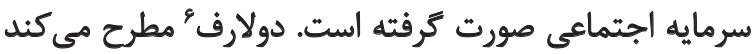

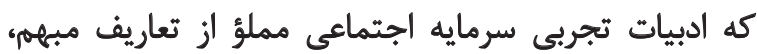

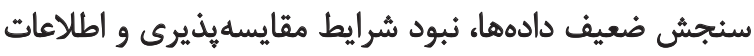

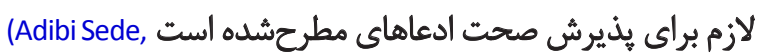
.Yazdkhasti, Khorasegani, \& Lotfalizade, 2009; Sabatini, 2005)

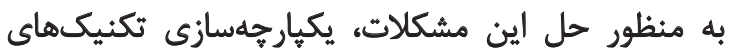

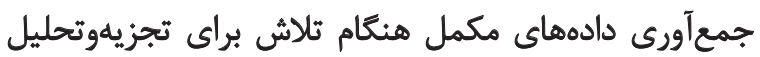

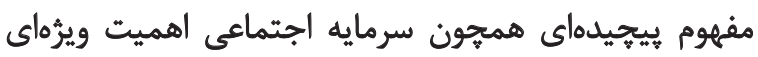

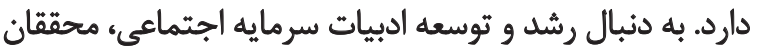

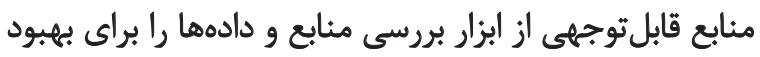

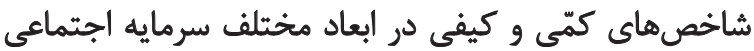

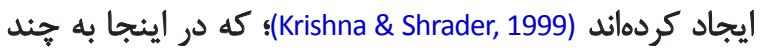

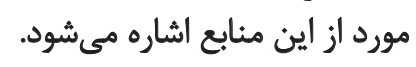

ابزار ارزيابي سروايه اجتماعى

اين ابزار مجموعه شاخصها و روشهاى مربوط به سطوح

6. Durlauf

7. The Social Capital Assessment Tool

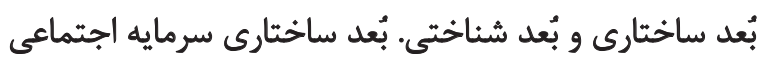

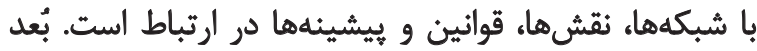

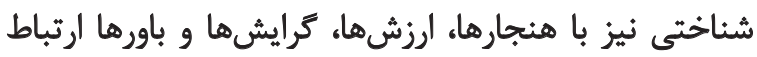

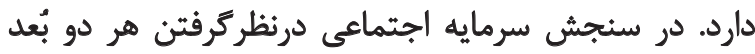

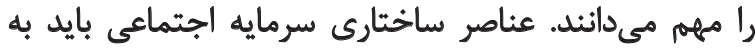

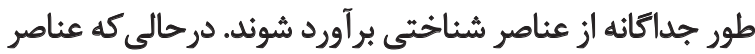

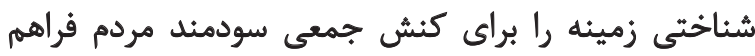

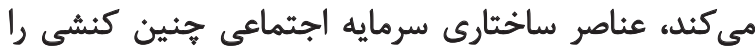

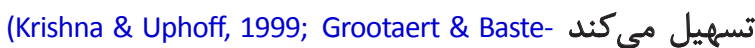

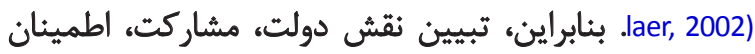

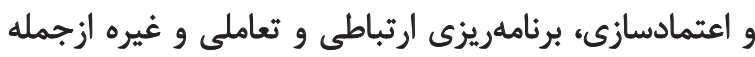

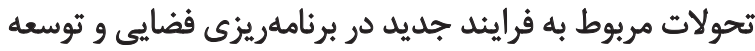

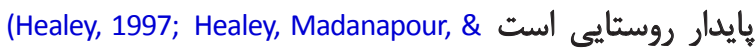
.Magalhaes, 1999; Amdam \& Amdam, 2000)

در اين زمينه نقش نهادها و نهادكرايى اهميت ويرّاي دارد.

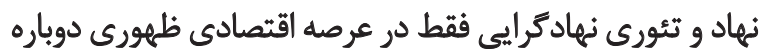

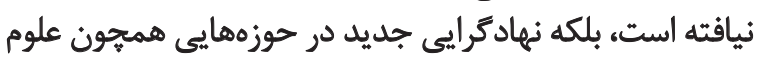

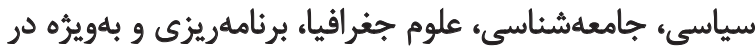

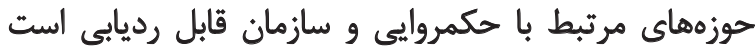
(Eftekhari, \& Badri, 2012)

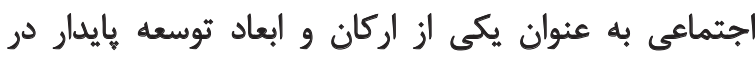

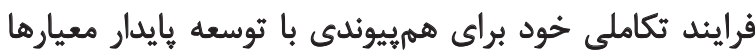

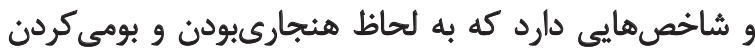
ضرورتى اجتناب ؤذير است.

شاخصهاى سرمايه اجتماعى در ثوسعه يايدار روستايى واكاوى متون نشان مىدهد توجه به ايجاد شاخصهاى باري

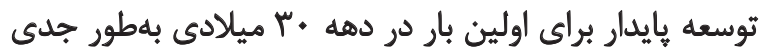

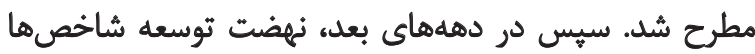

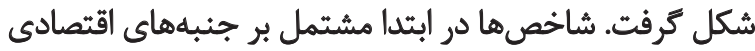

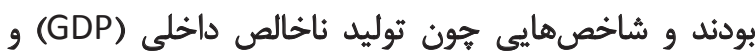

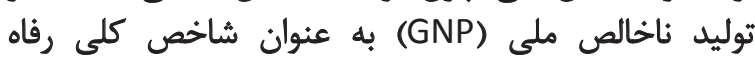

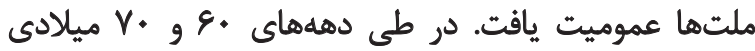

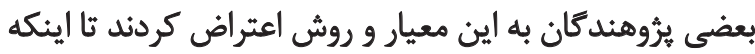

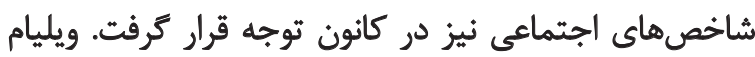

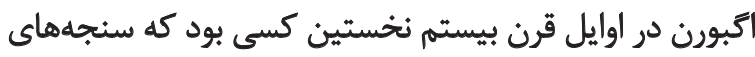

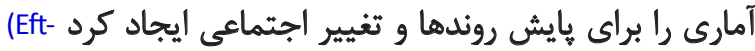
.ekhari et al., 2011; Choi \& Sirakaya, 2006)

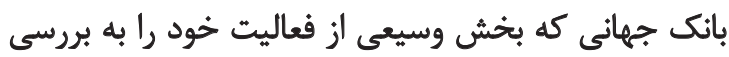

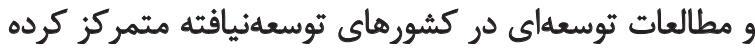

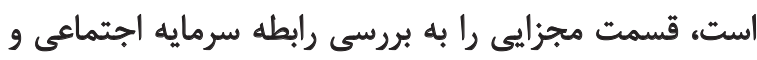

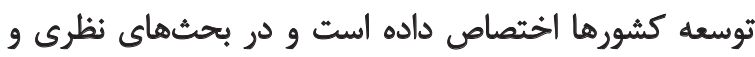
سنجشى و تأثير كذارى سرمايه اجتماعى، طرحها و وراده مطالعات 


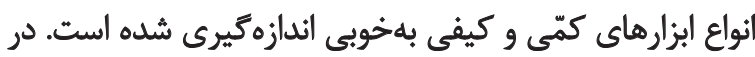

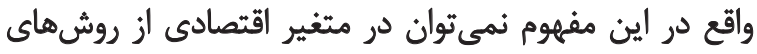

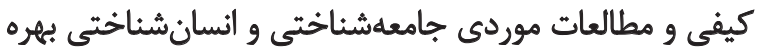

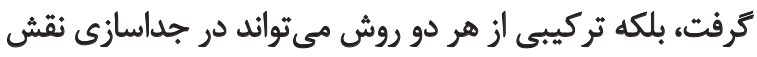

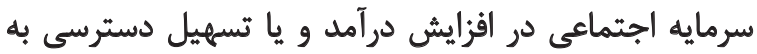

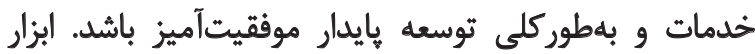

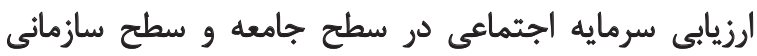

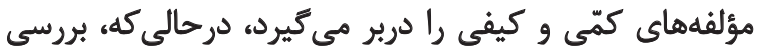

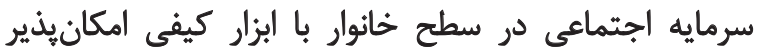

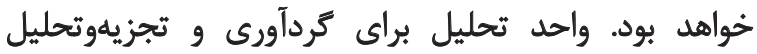

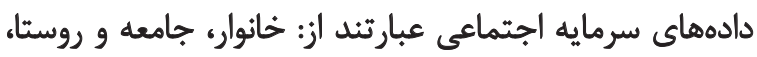
نههادها و سازمان وها (Grootaert \& Bastelaer, 2002).

از سوى ديكر، رز (1999) رويكرد جايكزين قابل ثأملى را به ابه

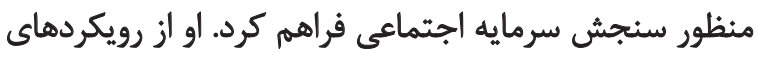
تئوريكى براى تجزيهوتحليل سرمايه اجتماعي بهرئ بهره

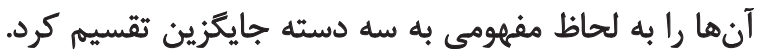

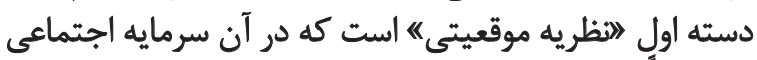

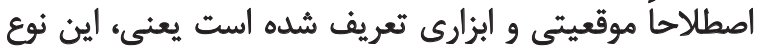

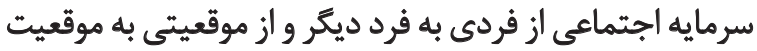

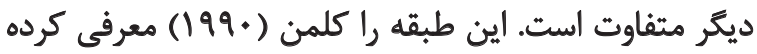

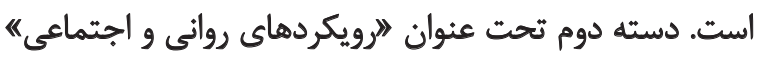

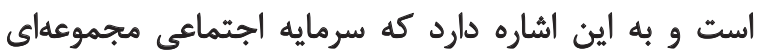

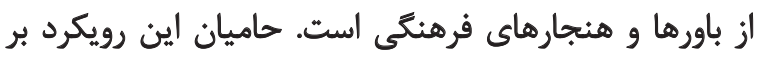

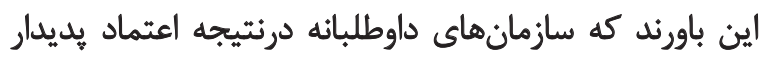
شدهاند؛ يعنى سرمايه اجتماعى در ذات بان با اعتماد برابر است. سرمايه اجتماعى از فردى به فرد ديكر متفاوت است، اما به طور

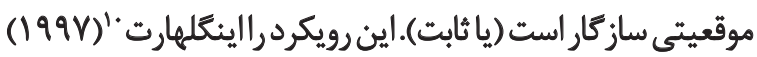

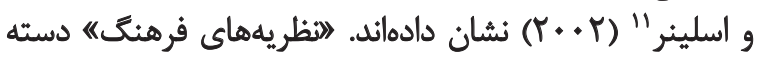

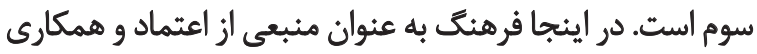

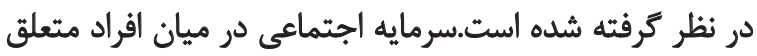

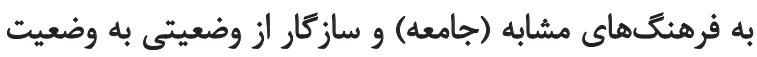

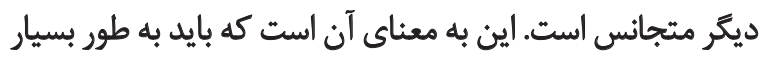

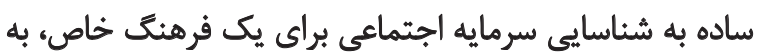

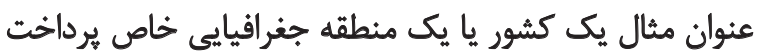

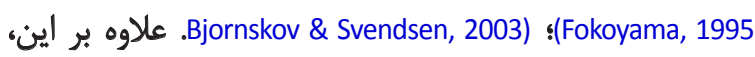

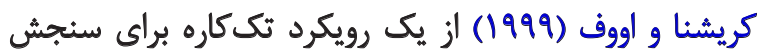

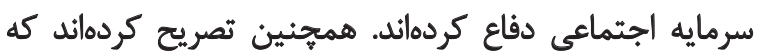

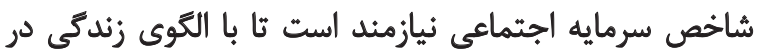

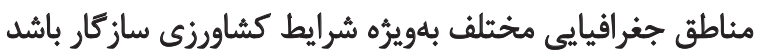

.(Hjollund \& Svendsen, 2000)

10. Ingelhart

11. Uslaner
سرمايه اجتماعى شناختى و ساختارى را در جوامع ذئنفع ازي

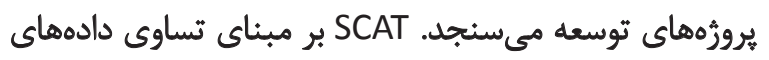

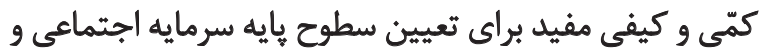

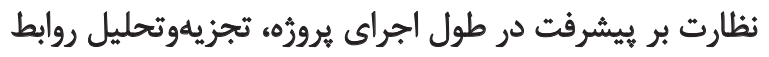

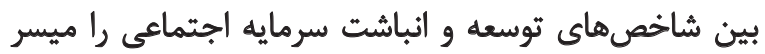

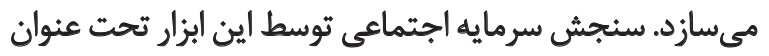

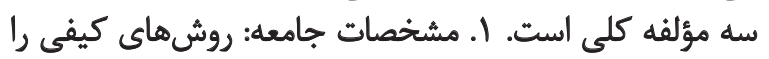

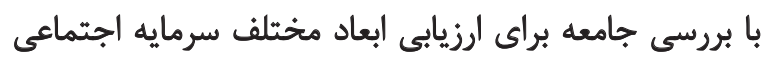

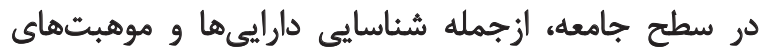

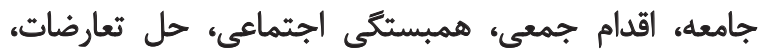

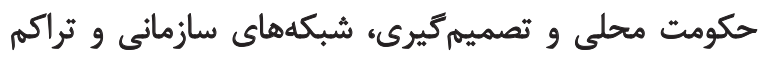

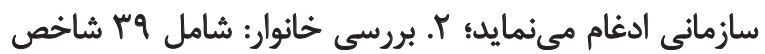

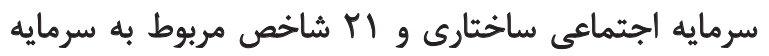

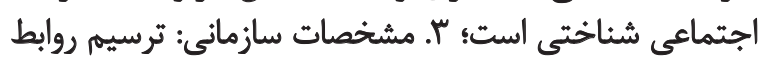

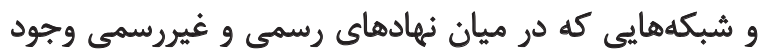

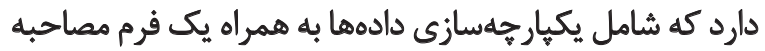

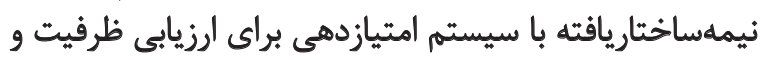

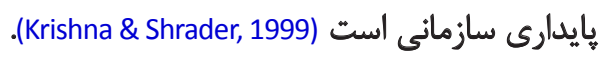

\section{بروسى اعضاى كاربران خانكّى ارويايى (EHCP)}

اين بررسى از سرمايه اجتماعى در 19 كشور اروباييى انجام

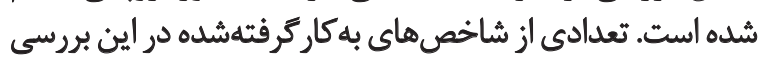

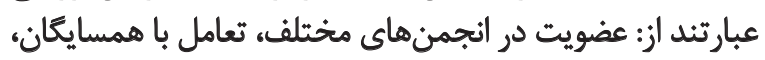

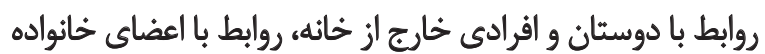
و جِكونكى كسب شغل توسط افراد (Healy, 2002).

\section{بروسى ارزشهاى جهائي (WVS)}

اين منبع توسط يك شبكه بينالمللى علوم اجتماعى هدايت

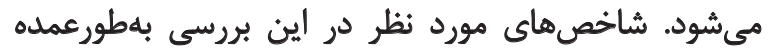

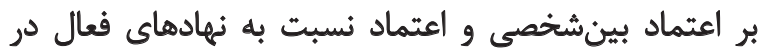

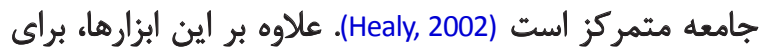

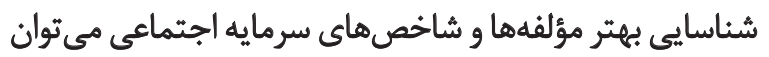

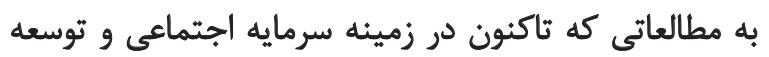
روستايى انجام شده است نيز استناد كرد. همانطور كه واكاوى ابزارهاى سنجش سرمايه اجتماعى

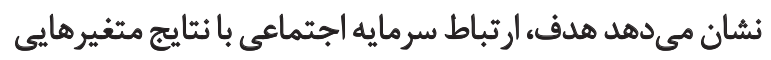

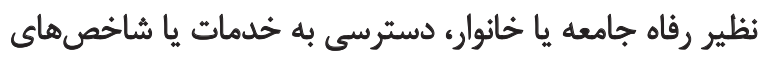

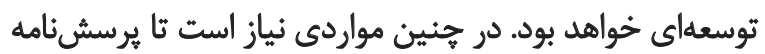

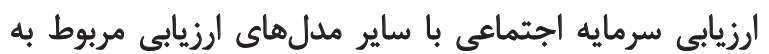

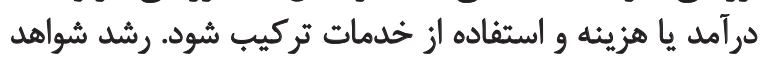

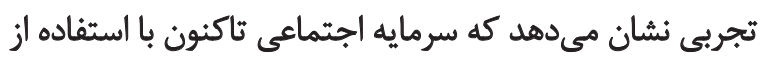

8. European Household Community Panel Survey 9. The World Values Survey 
جدول ا. برخى از مطالعات أنجامكرفته در زميئه سرمايه اجتماعي.

\begin{tabular}{|c|c|c|c|c|c|}
\hline نتايع & شاخصهاى كرفتهشده & موقعيت جغر افيايي & سال - - & نام يُؤهشكر & رديف \\
\hline \multicolumn{6}{|c|}{ سطح فرد وخانوار } \\
\hline اعتماد ميانفردى موجب افزايش تعهيات مدنى و ميزان اطمينان به نهادهاى & ت تعهيات مدنى، اعتماد ميانفردى، & أمريكا & 1994 & Brehm et al. & 1 \\
\hline شبكهناى اجتماعى، تاجران بخش كثاورزى را قادر به سوديرى بالاترىى & شبكه اجتماعى & مادأكاسكار & 1999 & Minten et al. & $r$ \\
\hline سرمايه اجتماعى در سطح روستاها اثرات مثبت بسيارى بر درآمد خانوارها & 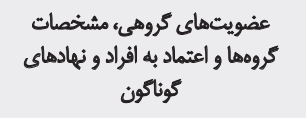 & ت ت تانزائيا & 1999 & $\begin{array}{l}\text { Narayan et } \\
\text { al. }\end{array}$ & r \\
\hline 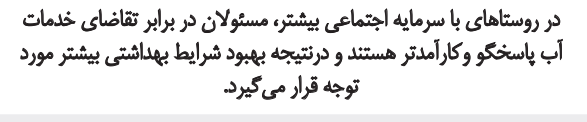 & عضويتها (كميت و كيفيت كروههاى & الثدوثزى & 1999 & Isham & 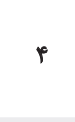 \\
\hline 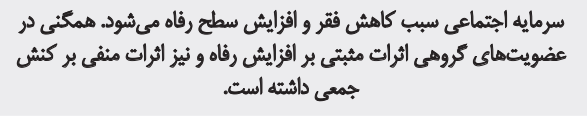 & 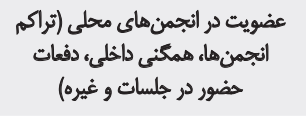 & الندونزى & 1999 & Grootaert & $\Delta$ \\
\hline 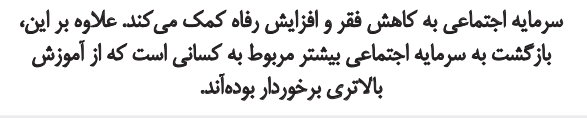 & عضويت در سازمانها و نهادهاى & بوليوي بوي & r... & $\begin{array}{l}\text { Grootaert } \\
\text { et al. }\end{array}$ & 8 \\
\hline شأحصهاى سرمايه اجتماعى به عثوان أعاد اساسى سرمايه اجتماعى هورد & 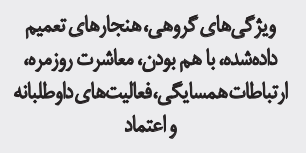 & غ غنا و اوكاثندا & $r+1$ & $\begin{array}{l}\text { Narayan } \\
\text { et al. }\end{array}$ & v \\
\hline 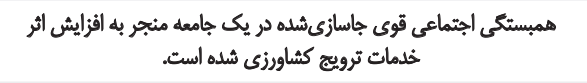 & اعتماد و همبستكيى الجتماعيى & 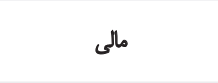 & r.ot & Reid et al. & 1 \\
\hline 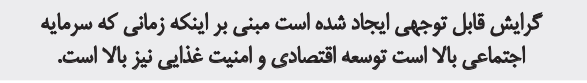 & هشاركت و اعتماد و ارتباط اجتماعى & يرو & r..t & Daiz et al. & 9 \\
\hline به نقش سرمايه اجتماعى در افزايش انكيزه براى توليد كشاورزى كارآمد به & عضويت أججمن & كامرون & r... & Binam et al. & 1. \\
\hline 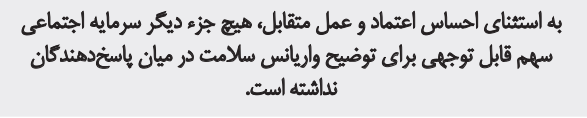 & 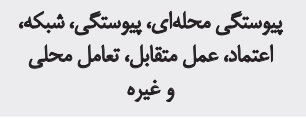 & استراليا & ror & Chavez et al. & 11 \\
\hline خانوارهاى با سطوح بالاتر سرمايه اجتماعى بعيد است كه به كرسنكى دهار & العثماد و عمل مثقابل و شبكههاى & أهريكا & ro.p & Martin et al. & ir \\
\hline 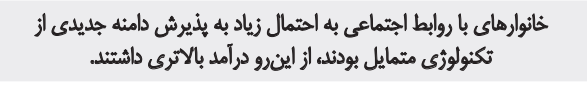 & ارتباط اجتماعى & جين & r.. & Wu et al. & ir \\
\hline 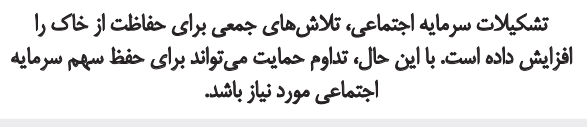 & هشاركت و عضويت در كروهها & فيليين & $r+\infty$ & Cramb & 10 \\
\hline \multicolumn{6}{|c|}{ سطح منطقلهاى يا جامعه } \\
\hline 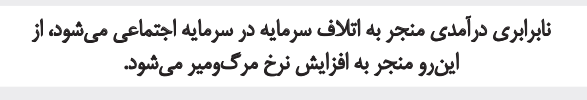 & عضويت در كرومهاي ذاوطلبانه و & أمريكا & 1994 & $\begin{array}{l}\text { Kawachi } \\
\text { et al. }\end{array}$ & la \\
\hline سرمايه اجتماعى بالاتر در ارتباط با كارائهتهاي عمل جمعى و توسعه سرزمينى & 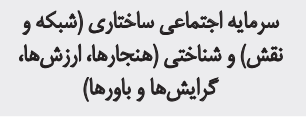 & هند & 1999 & $\begin{array}{l}\text { Krishna et } \\
\text { al. }\end{array}$ & 18 \\
\hline 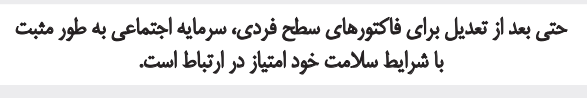 & اعتماد، عمل متقابل، عضويت نر كروه & أمريكا & 1999 & $\begin{array}{l}\text { Kawachi } \\
\text { et al. }\end{array}$ & iv \\
\hline 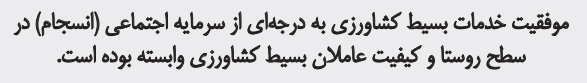 & انسجام|جتماعى & 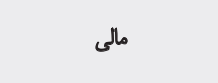 & r..r & Reid et al. & M \\
\hline
\end{tabular}


مورد توجه قرار كرفته است ثا در اين هجهارجوب روش رشيناسى

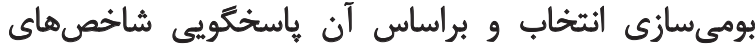

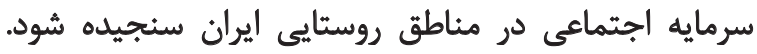

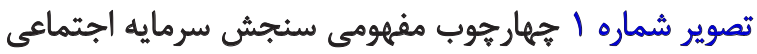

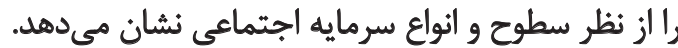

\section{"ا. روش شُشاسي تحقيق}

در مقاله حاضر با توجه به ماهيت تحقيق كه بومىسازى توسي

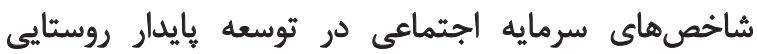
است از روششناسي توصيفي تحليلى و وييمايشى (نظرسنجي توسي

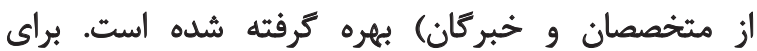

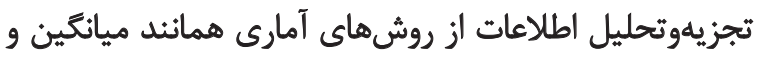

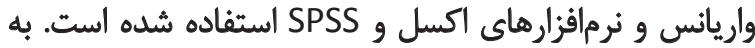

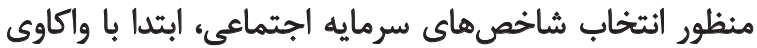

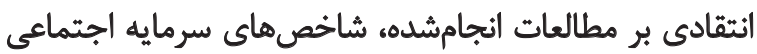

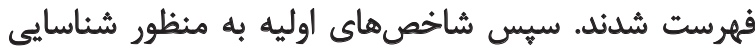

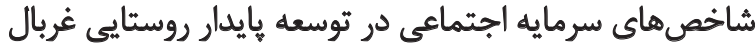
و به شاخص اصلى محدود شدند.

اين شاخصها با توجه به فراوانى تكرار در منابع كوناكون

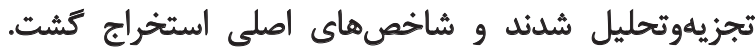

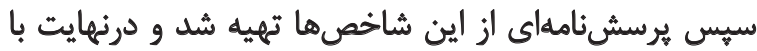

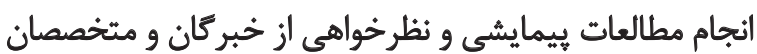

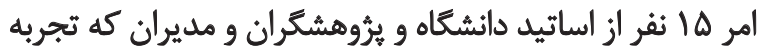

براى رسيلن به وضعيت فعلى روستاهاى ايران به لحاظ

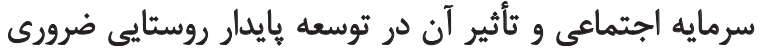

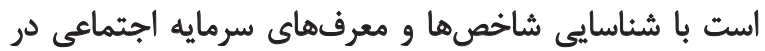

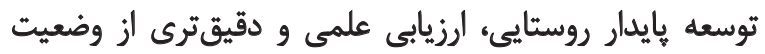

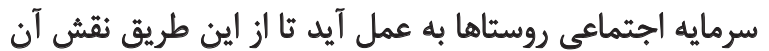

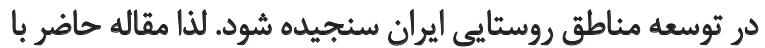
اتكا به رويكرد بومى سازى به دنبال تحقق اهداف ذكرشده است.

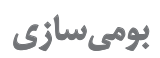

فرايند بومى سازى بر رهايى فكرى و ارزيابى مجدد متغيرهاى

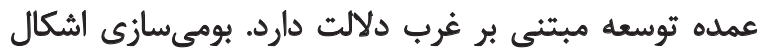

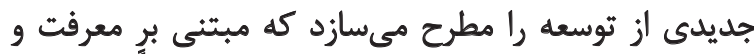

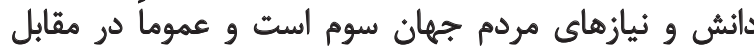

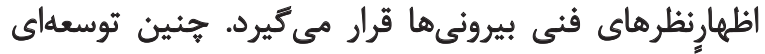

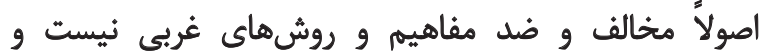
تجربيات بشرى را ناديده نمى

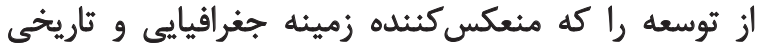

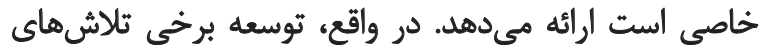

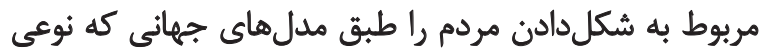

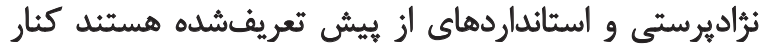

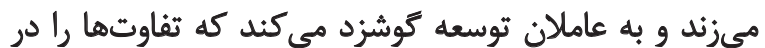

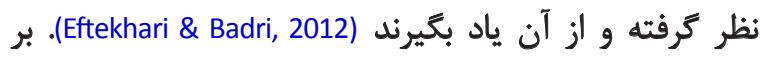
اين مبنا، جهارجوب مفهومى سطوح و انواع سرمايه اجتماعى بانى

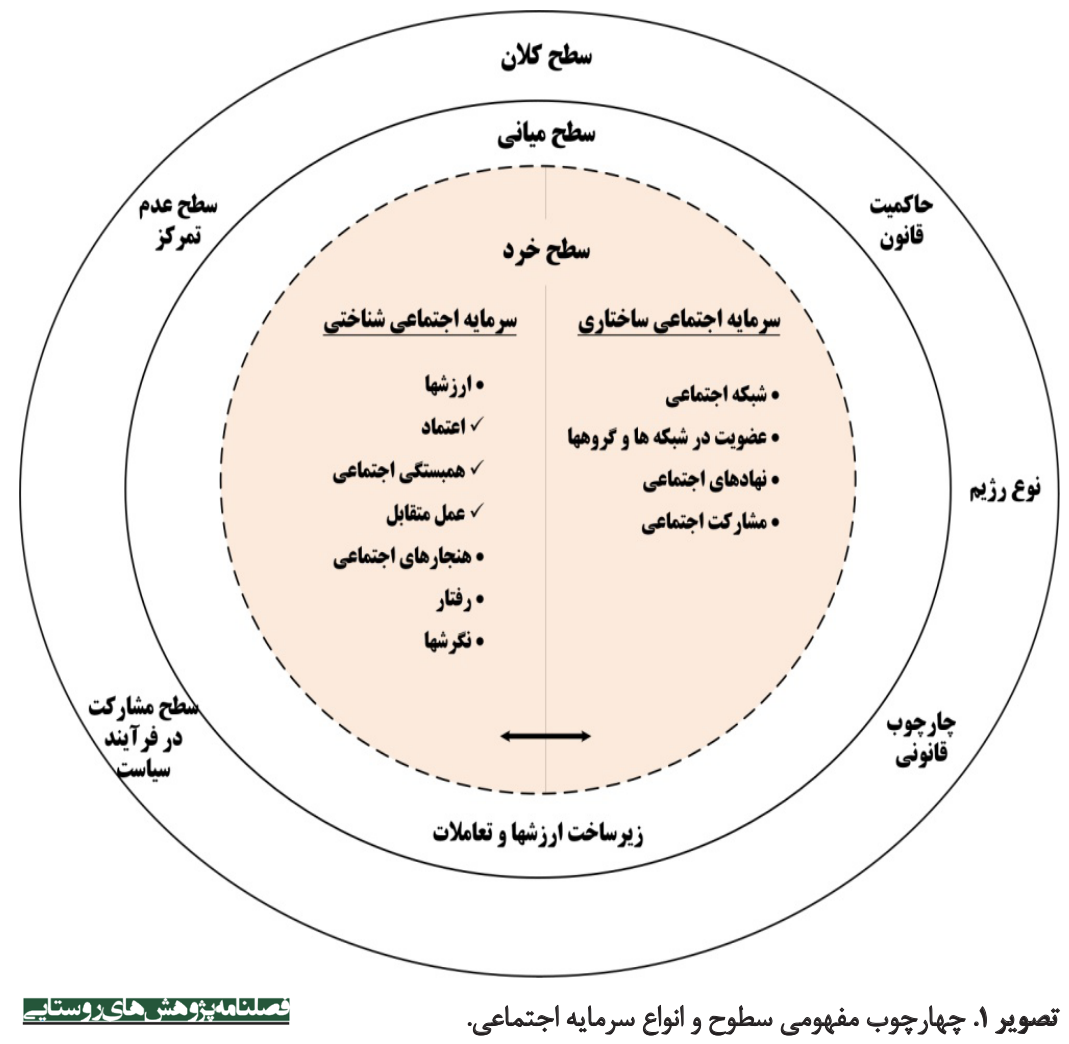




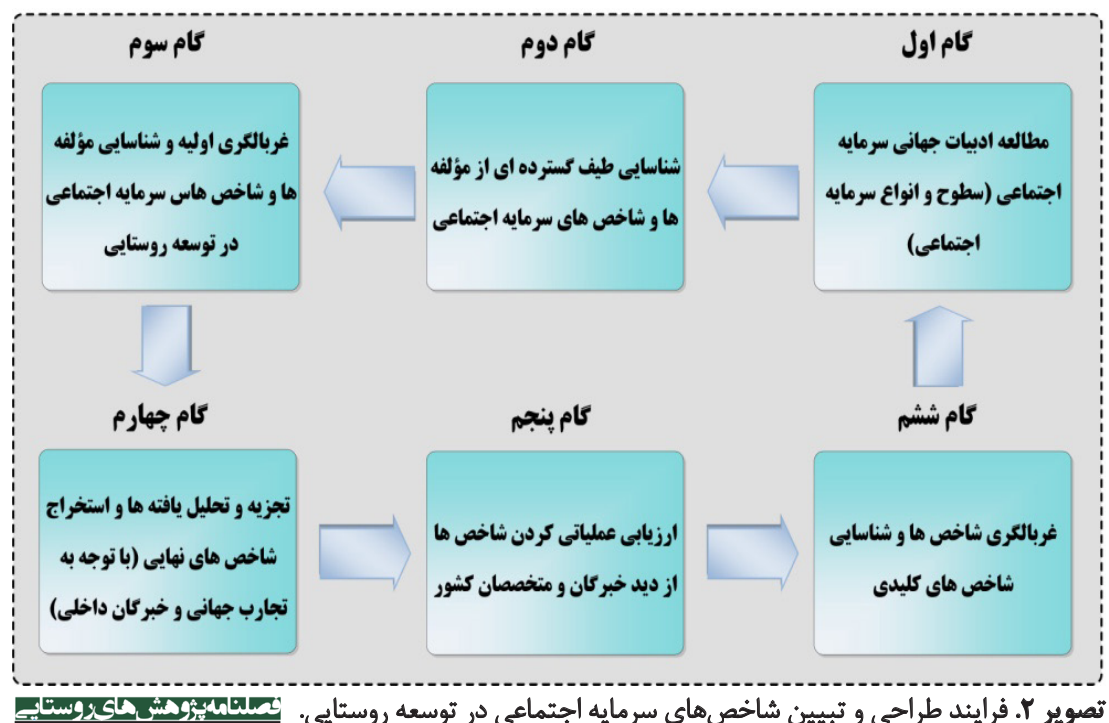

غربالترى اوليه و شناسايي مؤلفهها و شاخصهاى سرمايه

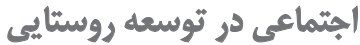

همانطور كه در بخش نظرى اشاره شد، ميان صاحبنظران

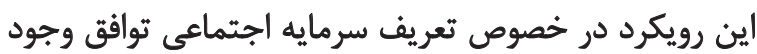

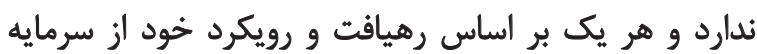

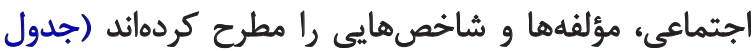

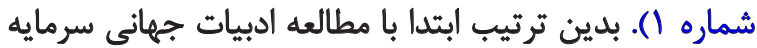

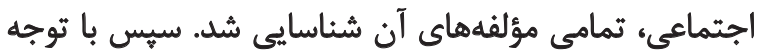

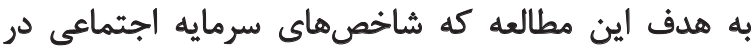

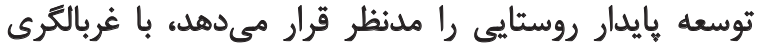

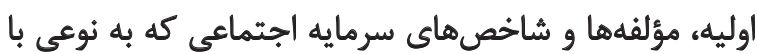

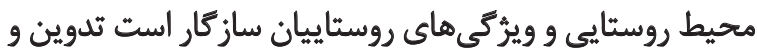

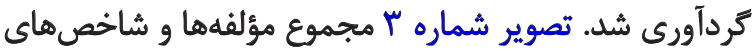

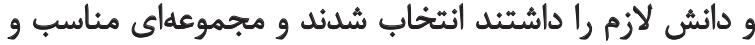

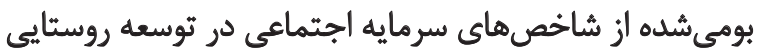

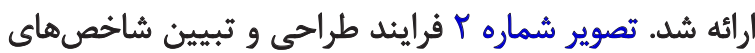

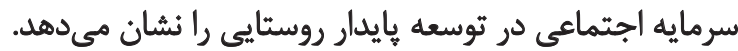

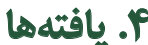

در مبانى نظرى تا حدودى به كام اول و دوم فرايند طراحي و وائو

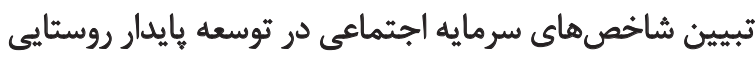

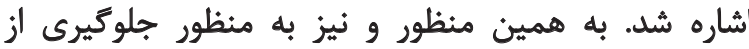
طولانىشدن فرايند مقاله، از كام سوم تا كام ششم ائن اين فرايند در توسعه روستايى شرح داده مى شود.

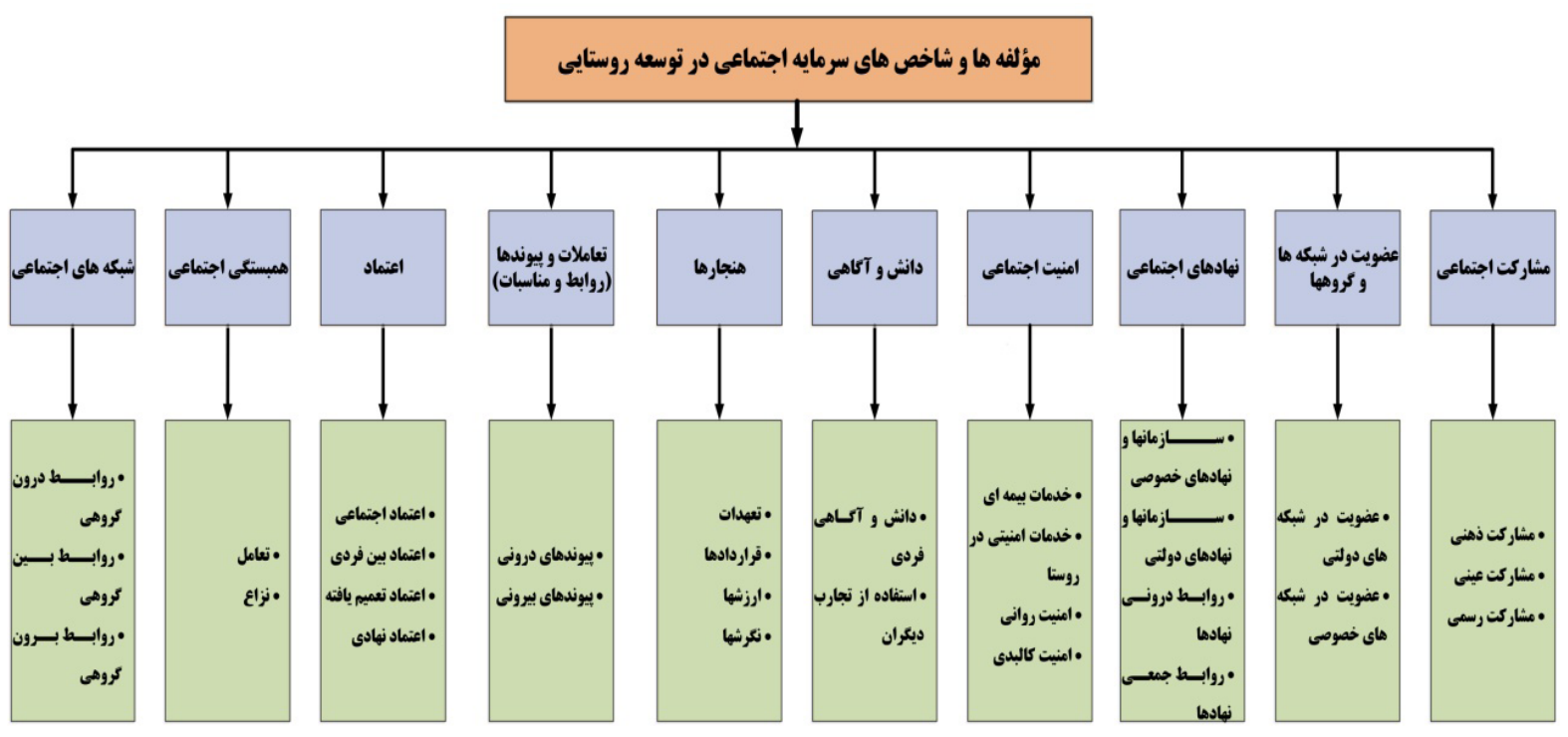


شرايط جغرافيايى و اجتماعى روستاهاى ايران استخراج شد.

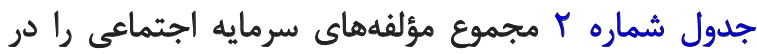

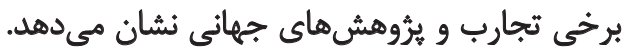
بومى و عملياتى كردن شاخصها از ديد شير كان و مثخصصان كشور

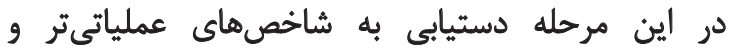

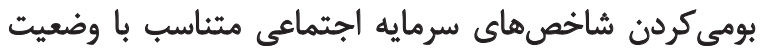

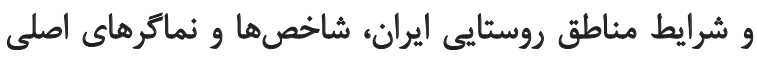

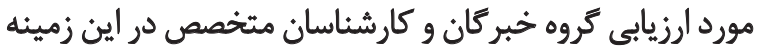

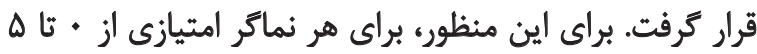

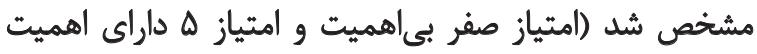

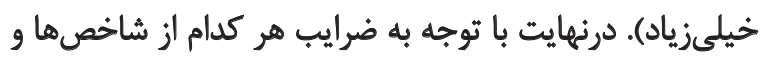

سرمايه اجتماعى در توسعه يايدار روستايى را نشان ميدهد. غربالكرى شاخصها و شئاسايى شاخصهاى كليدى

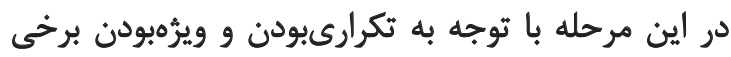

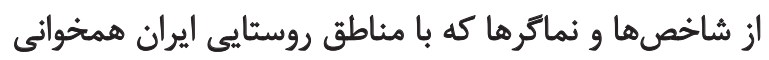

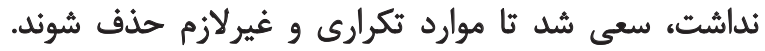

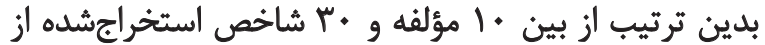

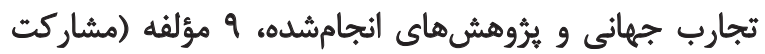

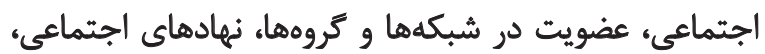

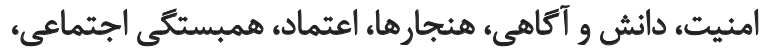

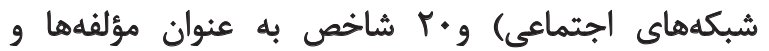
شاخصهاى نهايى با توجه درجه تكراريذيرى آنها و همجنين

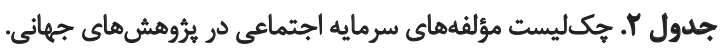

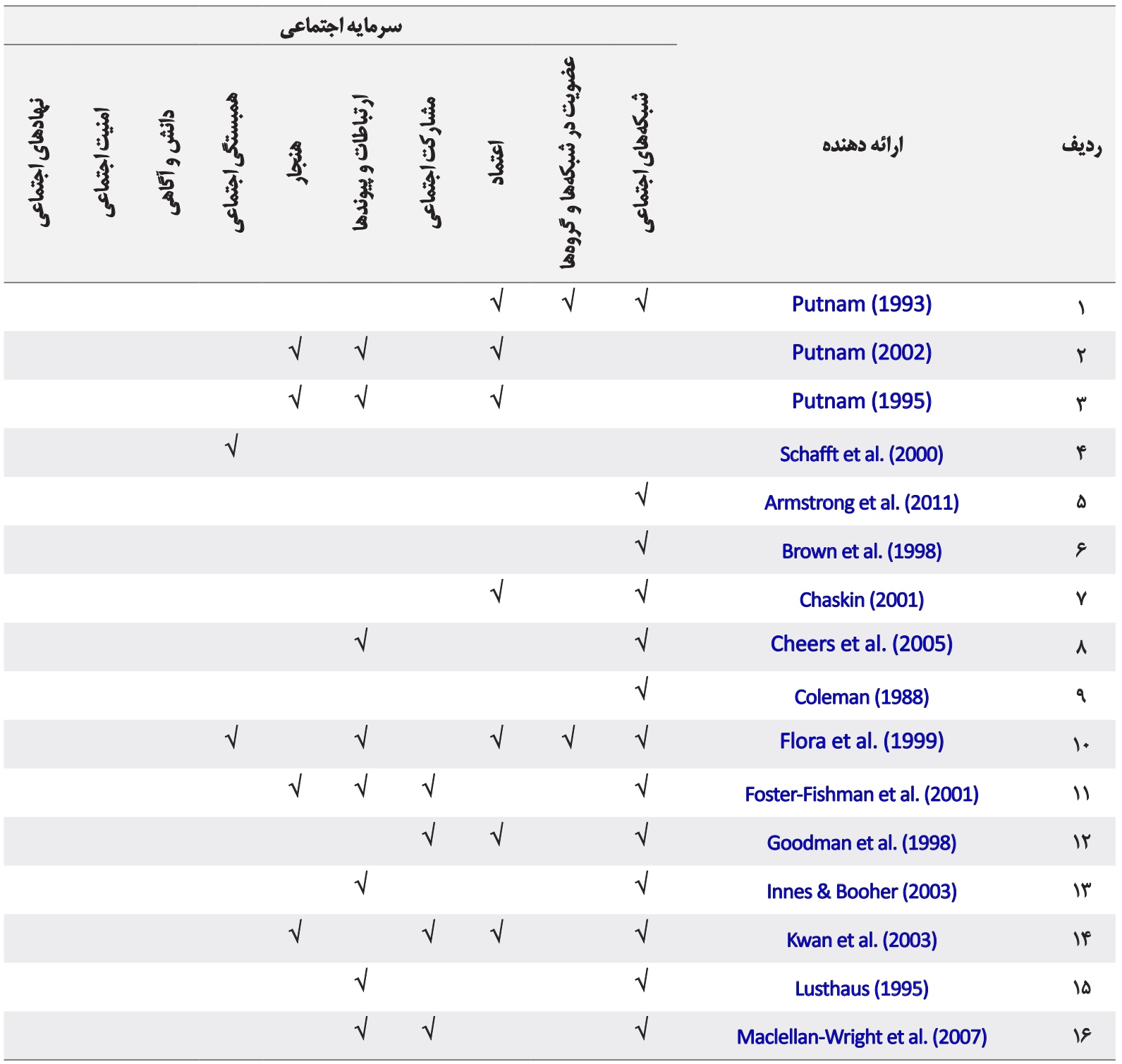




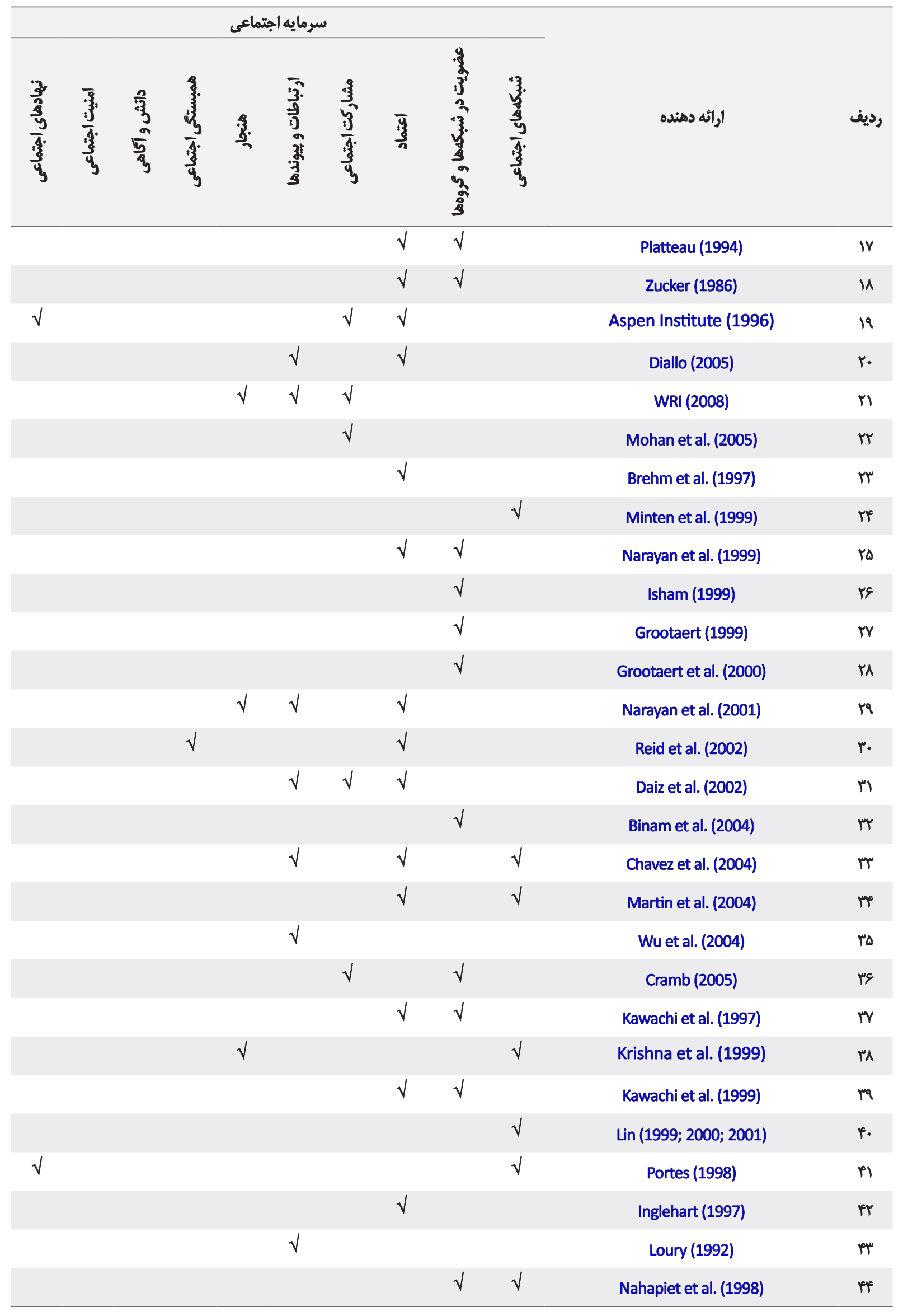




\begin{tabular}{|c|c|c|c|c|c|c|c|c|c|c|c|}
\hline \multicolumn{10}{|c|}{ سرمايه اجتماعى } & \multirow[b]{2}{*}{ أرائه دهنده } & \multirow[b]{2}{*}{ رديف } \\
\hline $\begin{array}{l}\frac{3}{3} \\
\frac{3}{y} \\
\frac{3}{4} \\
\frac{3}{4}\end{array}$ & $\begin{array}{l}\overline{9} \\
\frac{3}{3} \\
\frac{3}{3} \\
\frac{3}{4}\end{array}$ & $\begin{array}{l}\frac{a}{3} \\
\frac{5}{3}\end{array}$ & $\frac{3}{3}$ & 3 & $\begin{array}{l}\overline{3} \\
\overline{3} \\
\overline{3} \\
3 \\
3 \\
3 \\
3 \\
3\end{array}$ & $\frac{\sqrt[3]{3}}{\frac{3}{4}}$ & 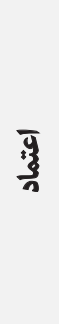 & $\begin{array}{l}.9 \\
3 \\
3^{3} \\
2 \\
3 \\
3 \\
3 \\
3 \\
3 \\
3 \\
3 \\
3 \\
3\end{array}$ & $\begin{array}{l}3 \\
\frac{3}{3} \\
\frac{3}{y} \\
\frac{3}{4} \\
\frac{3}{4}\end{array}$ & & \\
\hline & & & & & $\sqrt{ }$ & & & & & Pennar (1997) & Po \\
\hline$\sqrt{ }$ & & & & & & & & & & North (1990) & is \\
\hline \multirow[t]{10}{*}{$\sqrt{ }$} & & & & & & & & & & Casson et al. (2009) & iv \\
\hline & & & & $\sqrt{ }$ & & & $\sqrt{ }$ & & $\sqrt{ }$ & Ston (2001) & Pa \\
\hline & & & $\sqrt{ }$ & & & $\sqrt{ }$ & $\sqrt{ }$ & $\sqrt{ }$ & $\sqrt{ }$ & Bryant et al. (2002) & $p q$ \\
\hline & & & $\sqrt{ }$ & $\sqrt{ }$ & & $\sqrt{ }$ & $\sqrt{ }$ & & $\sqrt{ }$ & Harper (2002) & Q. \\
\hline & & & $\sqrt{ }$ & & & $\sqrt{ }$ & $\sqrt{ }$ & & $\sqrt{ }$ & Norris (2005) & (1) \\
\hline & & & & & & & & & $\sqrt{ }$ & Paldam (2001) & Qr \\
\hline & & & & & & & & & $\sqrt{ }$ & Fernandez et al. (2000) & هM \\
\hline & & $\sqrt{ }$ & & & & & & & & Offe et al. (2002) & af \\
\hline & & $\sqrt{ }$ & & & $\sqrt{ }$ & & $\sqrt{ }$ & & $\sqrt{ }$ & Falk et al. (2000) & $\Delta \Delta$ \\
\hline & $\sqrt{ }$ & & & & & & $\sqrt{ }$ & & & Bullen et al. (1998) & $\Delta$ \\
\hline p & 1 & r & 8 & 1. & iv & ir & rs & 10 & ra & مجموع امثيازات & $\Delta V$ \\
\hline
\end{tabular}

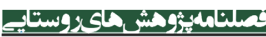

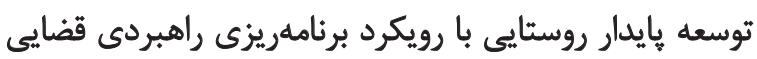

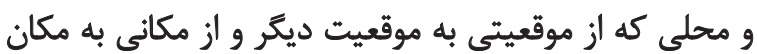

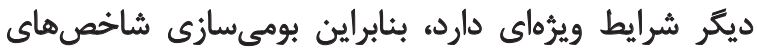

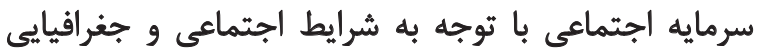

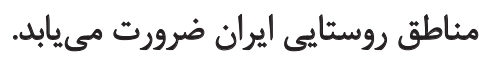

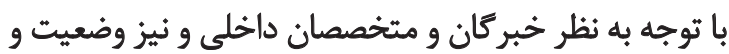

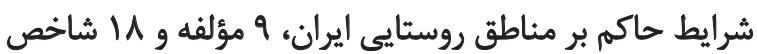

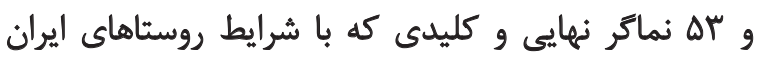

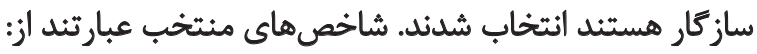

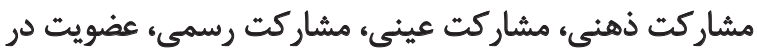

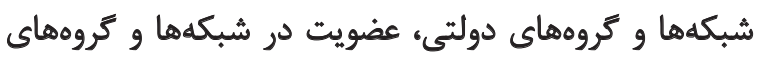

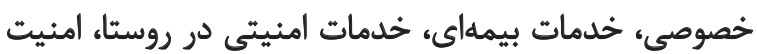

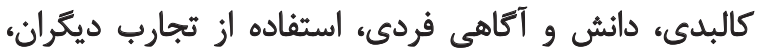

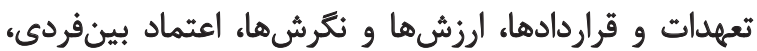

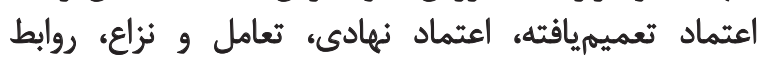

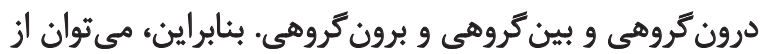

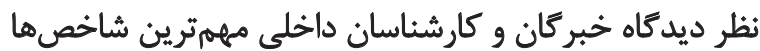

نماكرها و مجموع نمرههاى آنها و نيز ميانكين و انحرافمعيار

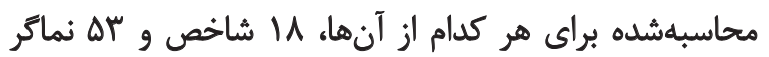

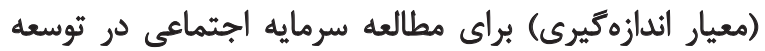

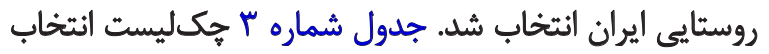

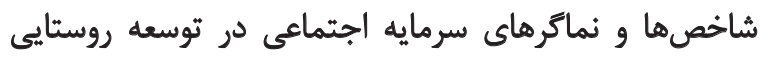

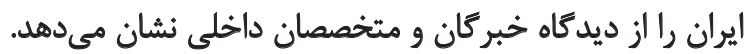

\section{تجزيلهوتحليل ياثتها و استخر اج شاخصهاي نهايى}

مؤلفهها و شاخصهاى سرمايه اجتماعى ابعاد كوناكونى دارند.

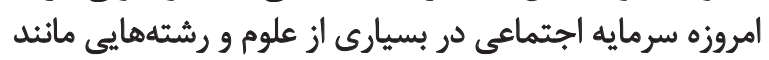

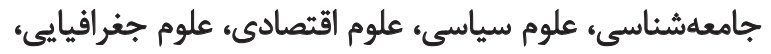

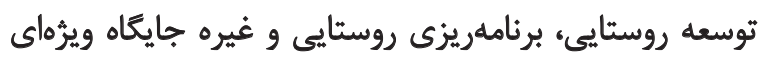

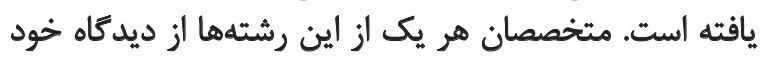

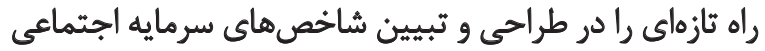

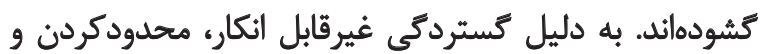

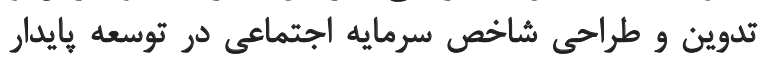

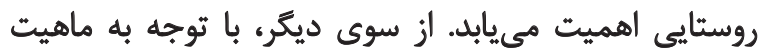




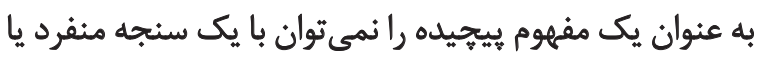

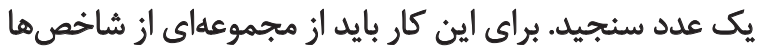
استفاده كرد تا بتوان ابعاد توناتون آن بائ را مقايسه كرد.

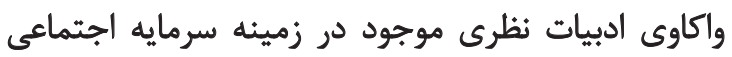

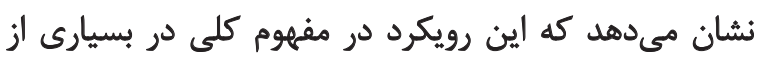

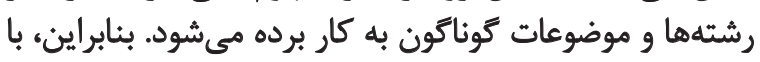

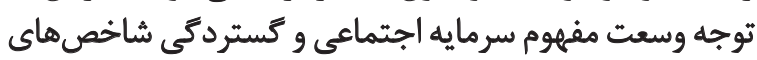

و نماكرهاى سرمايه اجتماعى در توسعه روستايى را در قالب جدول شماره F خلاصه كرد.

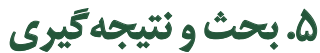

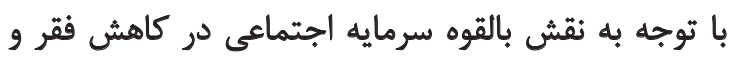

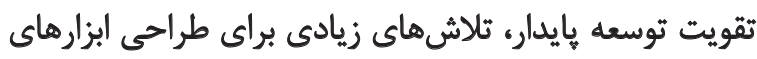

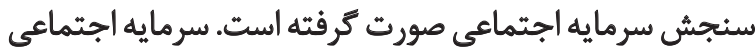

جدول r. جككليست انتخاب شاخصها و نماكرهاى سرمايه اجتماعى در توسعه روستايع ايران از ديدكاه خبر كان و متخصصان داخلى.

\section{معيار اندازمكيرى (نماكرها)}

ذهنيت افراد نسبت به مشاركت در حل مشكلات روستا

ميزان تفكر مشاركتى در حل مشكلات روستا

ميزان اراده جمعي در حل مشكلات روسشا

ميزان ثفكر برنامهريزى مشاركتى در حل مشكلات روستا

ميزان تفكر مشاركتى دولت و مردم وكارشناس براى بالابردن ظظرفيت توسعهاى روستا

ميزان أكاهى جمعى براى بالابردن ظرفيت توسعاى روستا

ميزان تفكر جمعى تصميمكيرى براى بالابردن ظرفيت توسعهاى روستا

ميزان تفكر صداقت جمعى براى بالابردن ظرفيت توسعلاي روستا

ذهيتيت افراد نسبت به عضويت در انجمنها، شوراها، تعاونى ها و غيره

ذهنيت افراد نسبت به مشاركت با شوراي أسلامي روستا

هينزان هشاركت بين كشاورزان

ميزان هشاركت درانتخابات شوراى روستا

هيزان هشورت با كشاورزان هوفت روستا

ميزان مشاركت در مراسمات مذهبي و محلى

ميزان مشاركت در فعاليتهاي خيريه در روستا

ميزان مشاركت در فعاليتهاي عامالمنفعه روستا

ميزان مشاركت در برئامههاي تسهيلكرى و ترويجي براي بالابردن ظرفيت توسعلاى روستا

ميزان عشاركت جمعى در شركت تعاوئى مصرف روستا

ميزان مشاركت در شركت تعاوثي توليدى روستا

ميزان مشاركت با اعضاى شوراى اسلامى روستا

ميزان مشاركت اعضاى شوراي روستا با يكلديكر

ميزان مشاركت در برنامهها و جلسات انجمن اوليا و مربيان ملرسه

ميزان مشاركت در طرحهاى عمرانى روستا مانثل ساخت مسجل، طرح هادى روستا و غيره

درصد عضويت در انجمنها و شبكههاى دولتى نسبت به كل شبكهها و كروههاى موجود در روستا

درصد عضويت در انجمنها، صنوف، اتحاديهها و شبكههاى بخش خصوصى نسبت به كل شبكه وا كروههاى خصوصى نر روستا

درصد عضويت در NGO أسبت به كل شبكهها و كروههاي خصوصى در روستا
ثاخصها

مؤلفهها

مشاركت

ذهنى مشار

هشاركت عينى

مشاركت

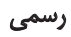

هشاركت الجتماعي 


\begin{tabular}{|c|c|c|}
\hline معيار اندازهكيرى (نماكر ها) & شاخصها & هؤلفهها \\
\hline 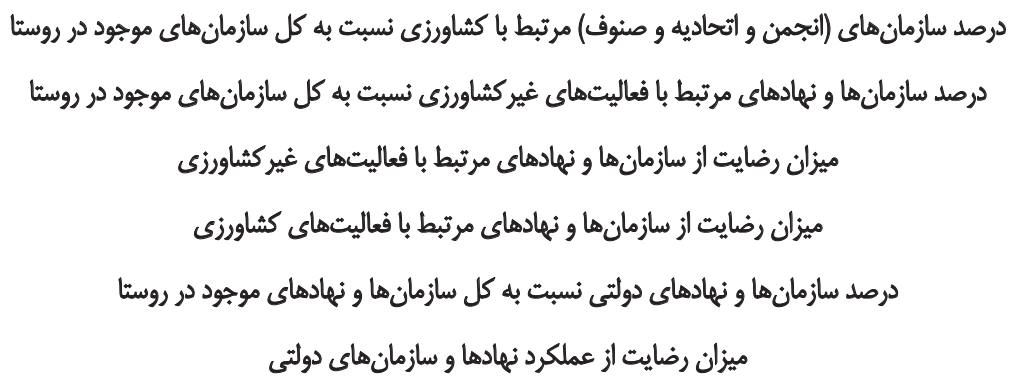 & و ونهازئهانها & نهادهاي اجتماعى \\
\hline 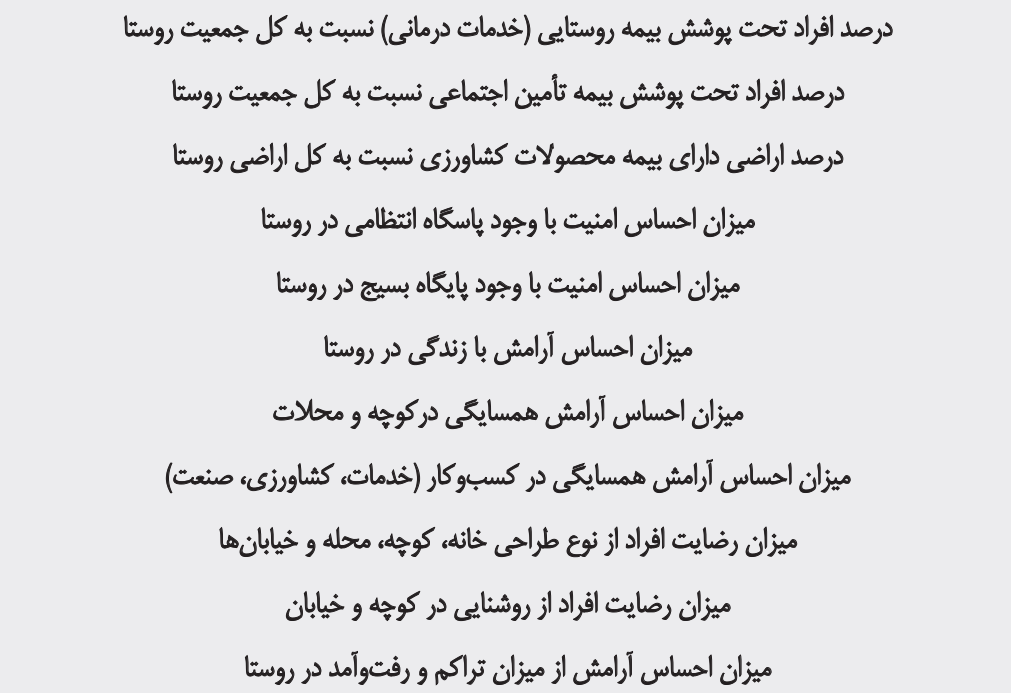 & خلمرات امنيتى & امثيت \\
\hline 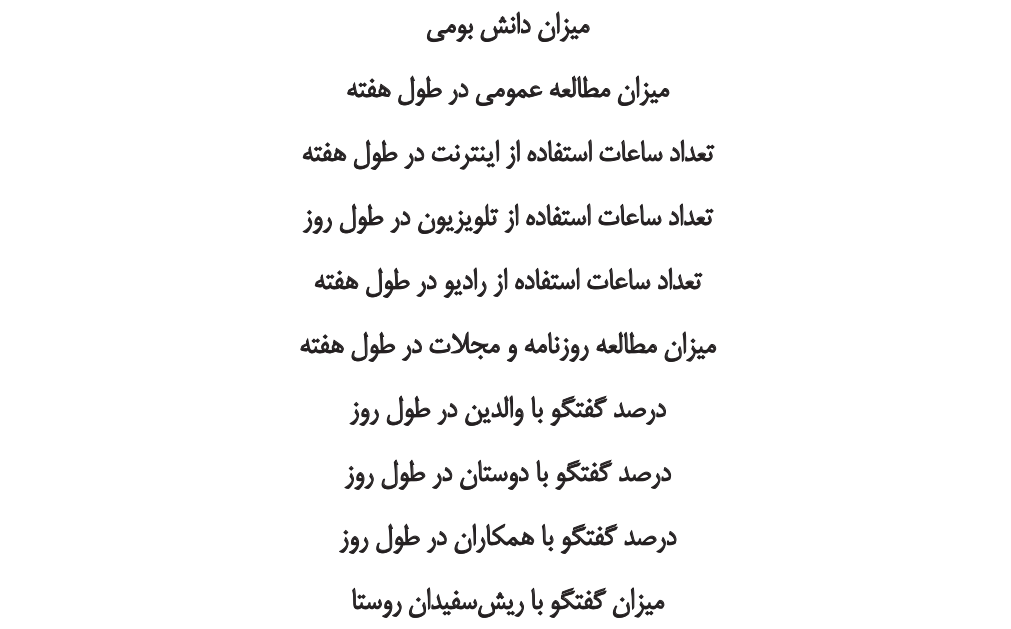 & الز أنجارفاده & دائش و أكاهى \\
\hline 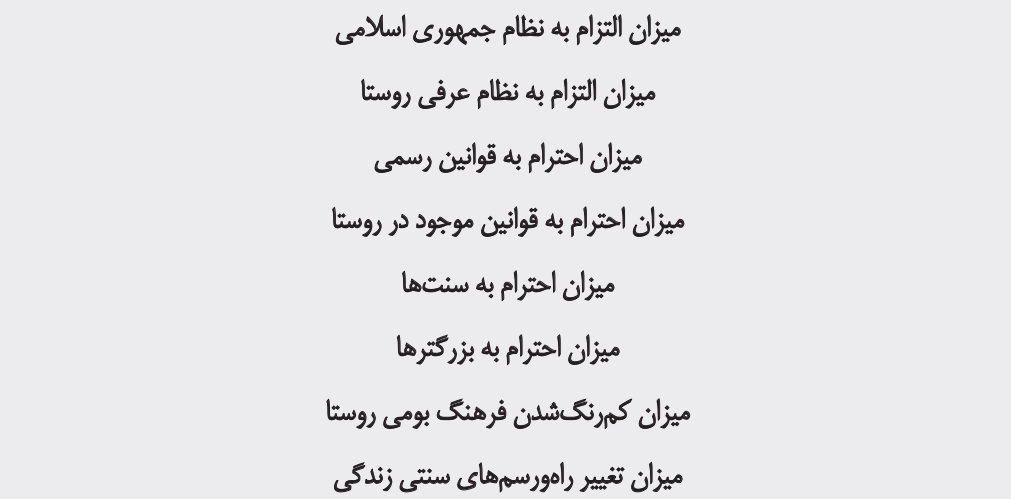 & 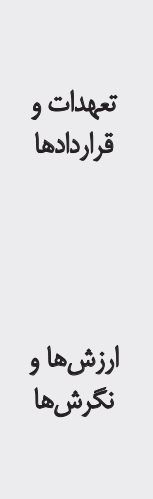 & 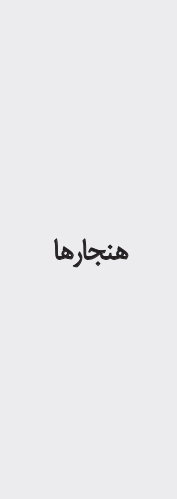 \\
\hline
\end{tabular}




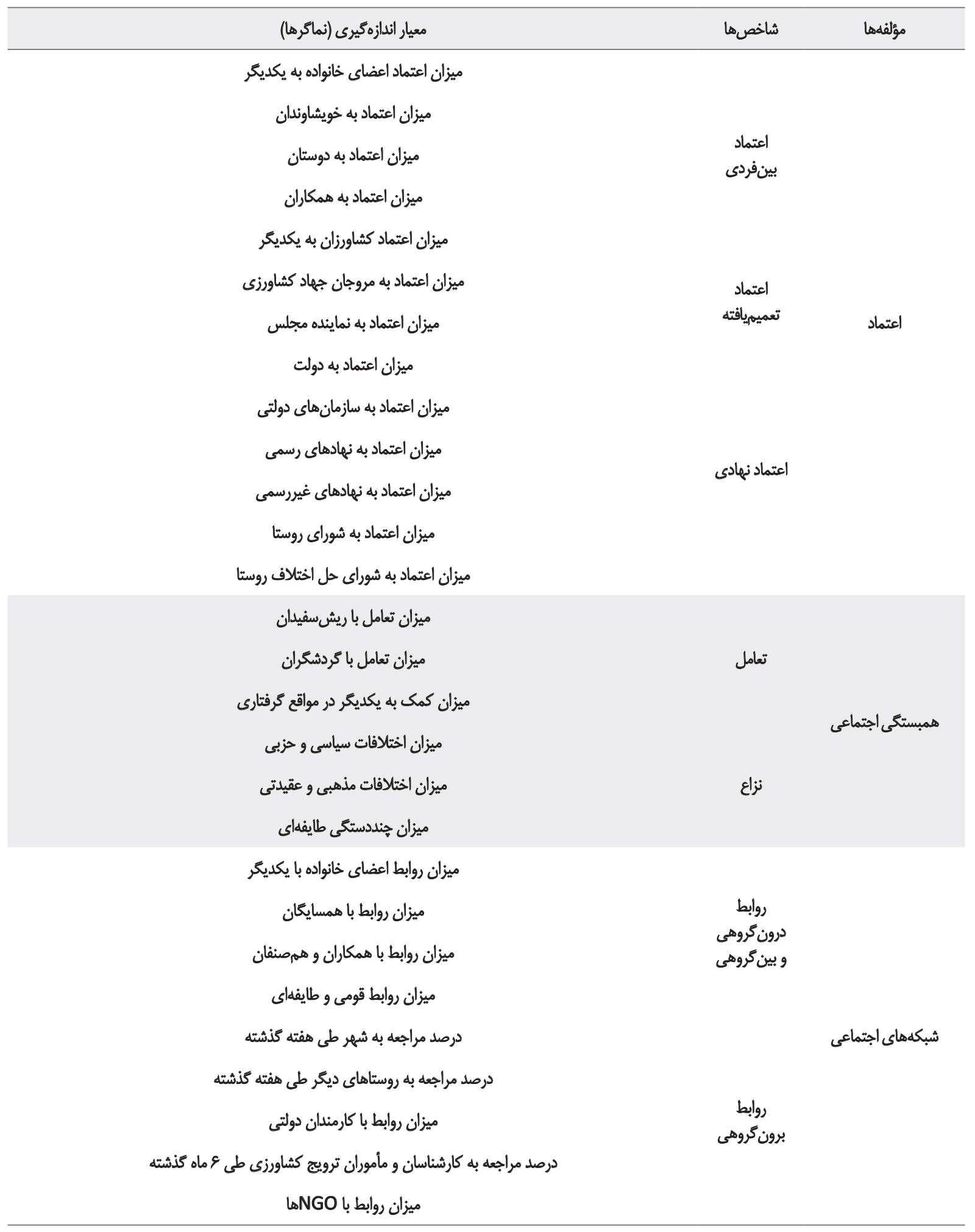

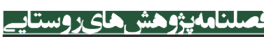

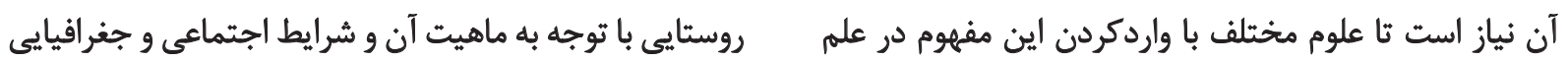

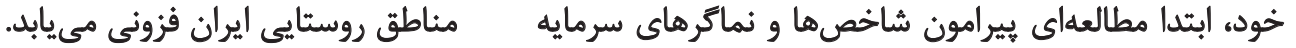

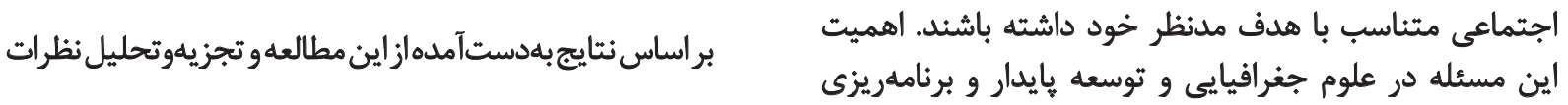


كروههاي خصوصى، خدمات بيمهاي، خدمات امنيتى در روستا،

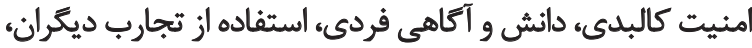

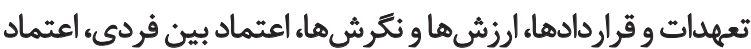

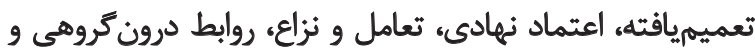
بين تروهى و برون كروهى را دربر مى تعيرد. روش به كار كرفتهشده در اين يُؤهش با نظريه بومىسازى
خبركان و متخصصان و كارشناسان داخلى اين حوزه، 9 مؤلفه و

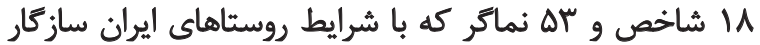

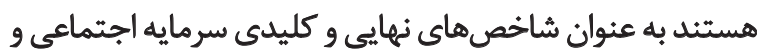

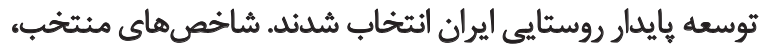

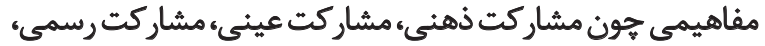

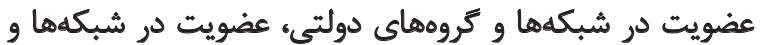

جدول f. مهمترين مؤلفهها، شاخصها و نماكر هاي سرمايه اجتماعى در توسعه روستايى ايران.

\begin{tabular}{|c|c|c|c|c|c|c|c|c|c|c|}
\hline \multirow{2}{*}{ है } & \multirow[b]{2}{*}{$\frac{5}{6}$} & \multicolumn{6}{|c|}{ فراوانى نظر خبر كان داخلى (درصد) } & \multirow[b]{2}{*}{ معيار اندازهيرى (نماترها) } & \multirow[b]{2}{*}{ شاخصها } & \multirow[b]{2}{*}{ مؤلفها } \\
\hline & & .". & š & $\xi^{2}$ & i & के & $\underline{\underline{\xi}}$ & & & \\
\hline \multicolumn{11}{|c|}{ ل مرمايه اجتماعى } \\
\hline . Na & e/RQ & PIV & $p / / v$ & $19 / N$ & • & • & - & ذهنيت افراد نسبت به مشاركت & & \\
\hline.$/ 29$ & $\varphi+1$ & $r / r$ & fi/v & TQ & · & . & • & ميزان ارادها جمعى در حل & & \\
\hline .199 & $r / 91$ & 每 & 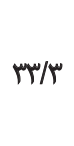 & ro & $N r$ & + & * & 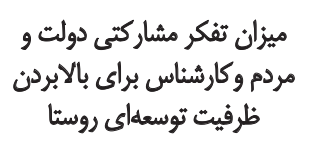 & مُهاركت & \\
\hline$\cdot / N$ & $r / V \Delta$ & $18 / \mathrm{V}$ & Q. & ro & $N r$ & • & • & 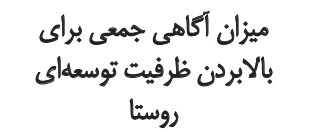 & & \\
\hline$\cdot(\pi)$ & $\Gamma / V \Delta$ & 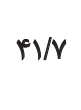 & Nr & r/ & $I E N$ & • & $\cdot$ & ذهنيت افراد نسبت به مشاركت & & \\
\hline . $/$ r & r & TA & Q. & rQ & - & - & . & ميزان مشاركت بين كشاورزان & & \\
\hline . $/ v 9$ & r/q1 & to & $P I / V$ & r/r & • & - & • & ميزان مشورت با كشاورزان & مشاركت & مشاركت اجتماعى \\
\hline 年 & $r / 19$ & FIN & Fi/ & Nr & Nr & • & • & ميزان مشاركت در فعاليتهاى & عينى ع & \\
\hline .194 & F/TA & $\pi / \pi$ & $\Delta N T$ & Nr & . & • & · & ميزان هشاركت در فعاليثتهاى & & \\
\hline 年 & P/N & $P M$ & r/r & ra & - & - & - & 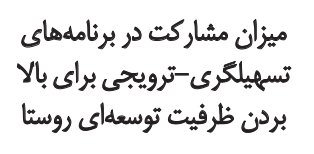 & & \\
\hline $1 / M F$ & $r / 91$ & FIN & ro & ro & • & Nr & • & ميزان مشاركت با اعضاىى & مشاركت & \\
\hline . Ma & $\% 1 \cdot 1$ & ( & $P I / V$ & ro & • & • & . & 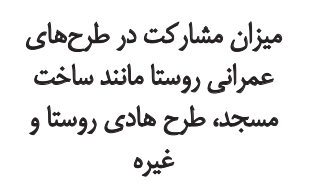 & & \\
\hline
\end{tabular}




\begin{tabular}{|c|c|c|c|c|c|c|c|c|c|c|}
\hline \multirow{2}{*}{ है. } & \multirow[b]{2}{*}{$\frac{c}{c_{k}}$} & \multicolumn{6}{|c|}{ فراوانى نظر خبركان داخلى (درصد) } & \multirow[b]{2}{*}{ معيار اندازوهيرى (نماكيرها) } & \multirow[b]{2}{*}{ شاخصها } & \multirow[b]{2}{*}{ مؤلفهها } \\
\hline & & $\stackrel{5}{5}$ & 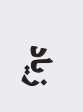 & $\frac{\xi}{\xi_{3}}$ & $z_{n}$ & $\sum^{2}$ & $\underline{\underline{E}}$ & & & \\
\hline \multicolumn{11}{|c|}{ سرمايه اجتماعى } \\
\hline $1 / 4$ & س & ro & ro & $M / \pi$ & $18 / N$ & - & • & 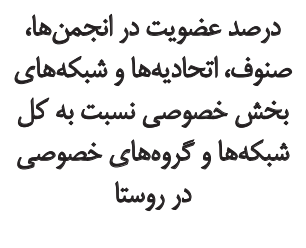 & خصوصى & عضويت در شبكهها \\
\hline $1 / \cdot 1$ & $\mathrm{r} / \Delta \mathrm{A}$ & ro & FIN & $N N^{r}$ & $18 / N$ & $N r$ & • & 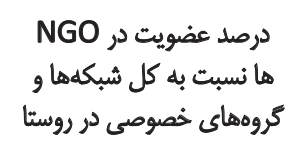 & & \\
\hline 1/90 & M/es & $P I / N$ & $\mid E / V$ & $1 E N$ & TQ & $N r$ & $18 / V$ & 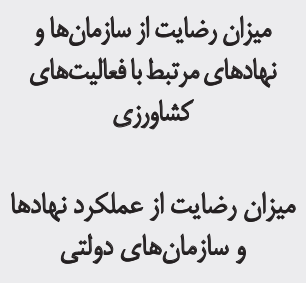 & 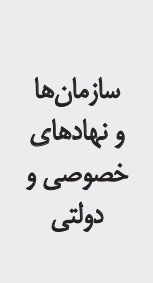 & نهادهاى اجتماعى \\
\hline$V / F$ & $H / Q$ & ra & $F / N$ & $N r^{r}$ & $18 / V$ & $1 \notin / V$ & • & 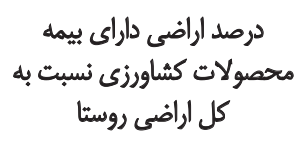 & & \\
\hline $1 / p q$ & سת/r & ro & $M / m$ & $N r^{r}$ & $18 / V$ & $\mid \notin / V$ & - & 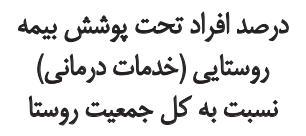 & خيملماى & \\
\hline$V / \Delta C$ & $r / 4 i$ & ra & $F I / Y$ & $N^{\mu}$ & $N{ }^{r}$ & $1 \& / V$ & - & 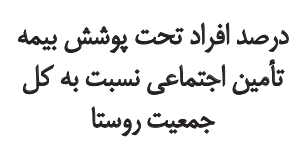 & & \\
\hline +/vq & $\mathrm{F} /+\mathrm{A}$ & $\pi / \pi$ & HIV & TA & • & - & . & ميزان احساس آرامشّ با زندكى & & \\
\hline •/AH & $F / N$ & FI/ & $M / r$ & ro & • & * & - & همسايكى دركوجه و مداس آرالات & خدات درو روستيتى & امنيت \\
\hline . Iav & $P / Q$ & $\Delta N{ }^{W}$ & 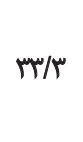 & $N r^{\mu}$ & . & - & . & 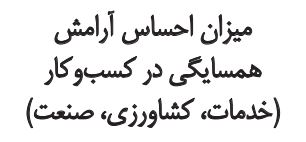 & & \\
\hline עיז & $r / \Lambda \&$ & $\mid \& / V$ & ra & $\pi / \pi$ & $N{ }^{r}$ & $\mid g / V$ & • & 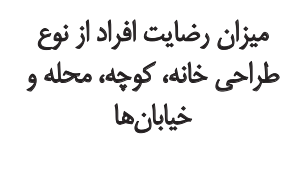 & امنيث كالبدى & \\
\hline ( & $m /$ & - & $\Delta$. & $1 E / V$ & $m / \mu$ & + & • & ثيزان احساس آرامش از ميزان & & \\
\hline
\end{tabular}




\begin{tabular}{|c|c|c|c|c|c|c|c|c|c|c|}
\hline \multirow{2}{*}{ है } & \multirow[b]{2}{*}{$\frac{c}{6}$} & \multicolumn{6}{|c|}{ فراوانى نظر خبر كَان داخلى (درصد) } & \multirow[b]{2}{*}{ معيار الندازهيكيرى (نماكّرها) } & \multirow[b]{2}{*}{ شاخمصها } & \multirow[b]{2}{*}{ مؤلفهها } \\
\hline & & : & 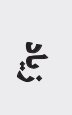 & $\frac{\xi}{\xi}$ & $z_{n}$ & ?h. & $\underline{\underline{\varepsilon}}$ & & & \\
\hline \multicolumn{11}{|c|}{ سرمايه اجتماعى } \\
\hline$y+v$ & r/gs & ra & $m / r$ & ra & $\mid g / V$ & $\cdot$ & • & ميزان دانش بومى & & \multirow{9}{*}{ دائش و آكاهي } \\
\hline $1 / M F$ & 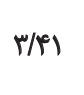 & YA & To & $18 N$ & & . & . & هيزان مطالعه عمومي در طول & & \\
\hline $1 / 10$ & سח/R & $1 E / V$ & TA & $P V / N$ & $N r$ & $N r$ & • & تعداد ساعات استفاده از ايتترنت & & \\
\hline $1 / \pi V$ & $r / A$ & $N N^{N}$ & $M / T$ & $P V /$ & • & $N{ }^{r}$ & $N r$ & تلكداد ساعات استُفاده از & 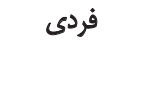 & \\
\hline $1 / \pi$ & $1 / 9$ & . & $P I N$ & $\pi / \mu$ & $N r^{r}$ & $N{ }^{r}$ & $N^{r}$ & تعلفاد ساعات استُفاده از راديو در & & \\
\hline $1 / 4 F$ & $r / 9$ & • & $F I N$ & 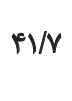 & • & • & $I E N$ & ميزان مطالعه روزنامه و مجلات & & \\
\hline $1 / \Delta A$ & r/ME & ro & $I E N$ & $r r / r$ & $N r$ & $N r$ & $N r$ & 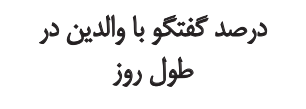 & \multirow{3}{*}{ أز أجاربفاده } & \\
\hline $1 / M \pi$ & $r / 18$ & $N{ }^{\mu}$ & Q. & $\mathcal{N} r^{r}$ & $18 / V$ & $19 / V$ & • & درصد كفتكو با همكاران در & & \\
\hline $1 / m$ & r/ME & $I E N$ & TA & $m / \mu$ & $N r$ & $I E N$ & - & ميزان كَثتكو باريشسفيدان & & \\
\hline $1 / M E$ & $r / 9)$ & $m / \pi$ & $\pi / T$ & - & $\pi / T$ & • & - & ميزان احترام به قوانين موجود & \multirow{5}{*}{ 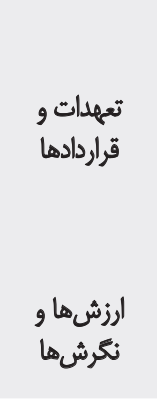 } & \multirow{5}{*}{ هنجارها } \\
\hline $1 / \pi$ & rise & $\mid E N$ & D. & $N{ }^{r}$ & $18 / N$ & $N{ }^{\mu}$ & $\cdot$ & ميزان التزام به نظام عرفى & & \\
\hline $1 / M E$ & $r / \Delta$ & $P I N$ & TA & TA & • & $N T^{H}$ & $\cdot$ & هيزان احترام به قواثين روسهى & & \\
\hline $.1 N$ & T/VO & ro & TA & $\Delta$. & • & • & • & ميزان احترام به سنتها & & \\
\hline . 199 & r/91 & $I E / V$ & ES/ & $N{ }^{r}$ & $N{ }^{r}$ & . & • & ميزان احترام به بزركترها & & \\
\hline$\cdot M$ & PIS & $M / \mu$ & $\Delta$. & $18 / N$ & • & • & $\cdot$ & ميزان اعتماد اعضاي خانواده & \multirow{3}{*}{ اعتين } & \multirow{7}{*}{ اعتماد } \\
\hline .119 & f & Pr & TA & 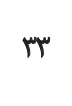 & • & • & • & هيزان اعتماد به خويشاوندان & & \\
\hline . & P/IE & Q. & $I E N$ & 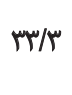 & • & • & • & ميزان اعتماد كشاورزان به & & \\
\hline . AN & Phe & $P I / N$ & $M T / r$ & TA & • & . & . & ميزان اعتماد به هروجان جهاد & تعميهي⿻افته & \\
\hline $1 / f$ & $r / A r$ & $r / N$ & 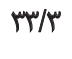 & $\cdot$ & $I E / V$ & $N{ }^{\mu}$ & $\cdot$ & 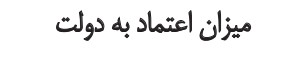 & \multirow{3}{*}{ اعتماد نهادى } & \\
\hline $1 / P A$ & T/NO & $\Delta$. & $N r^{r}$ & $18 N$ & $1 E / N$ & $N r$ & • & ميزان اعثماد به شوراى روستا & & \\
\hline $1 / 18$ & $r / \Delta A$ & ro & $m / r$ & $18 N$ & ro & • & • & هيزان اعتماد به شوراى حل اخلاف روستا & & \\
\hline
\end{tabular}




\begin{tabular}{|c|c|c|c|c|c|c|c|c|c|c|}
\hline \multirow{2}{*}{ है. } & \multirow[b]{2}{*}{$\frac{c}{c_{k}}$} & \multicolumn{6}{|c|}{ فراوانى نظر خبر كان داخلى (درصد) } & \multirow[b]{2}{*}{ هعيار اندازهيري (نماكيرها) } & \multirow[b]{2}{*}{ شاخصها } & \multirow[b]{2}{*}{ مؤلفهها } \\
\hline & & $\stackrel{4}{5}$ & ئ. & $\frac{\xi}{\xi_{3}^{2}}$ & $\boldsymbol{z}$ & की & $\underline{\underline{\xi}}$ & & & \\
\hline \multicolumn{11}{|c|}{ سرمايه إجتماعى } \\
\hline $1 / 19$ & $M / M E$ & $\pi / T$ & ه. & - & $18 / N$ & + & • & ميزان كمك به يكلديكر در & & \\
\hline •/ar & P/IE & $\Delta$. & ro & $N r^{\infty}$ & - & $N r$ & $N{ }^{m}$ & ميزان جنددستكى طايفهاى & تعامل و نزاع & همبستكى اجتماعى \\
\hline.$/ 19$ & $p$ & Q. & $I E N$ & $M / T$ & - & - & • & ميزان روابط اعضاى خانواده با & & \\
\hline$\cdot / M^{r}$ & $p$ & ra & ه. & ro & - & - & $\cdot$ & ميزان روابط با همسايكان & روابط & \\
\hline$+/ v 9$ & $\varphi / \cdot \Lambda$ & 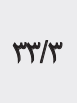 & $F I / N$ & ta & • & - & $\cdot$ & ميزان روابط با همكاران و & و يدرو كروهي & \\
\hline . / 9 & $r / * 1$ & 每 & PIN & TA & - & - & - & هيزان روابط قومى و طايفهاى & & \\
\hline$+/ 4$ & M/\&g & $\pi / \mu$ & 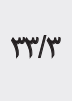 & to & $N r$ & + & - & درصد مراجعه به ثهر طي هفته & روابط & \\
\hline$\cdot / M$ & עז/ץ & ro & ro & $f i / N$ & $N{ }^{r}$ & + & • & 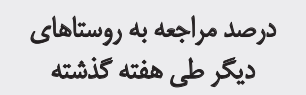 & برون كروهي & \\
\hline
\end{tabular}

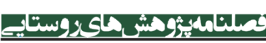

با توانمندسازى روستاييان، اعتمادبهنفس و خودباورى در آنها

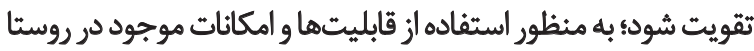
ظرفيتسازى صورث كيرد؛ از طريق تعاملات همكارى جويائه، اعتماد بينشخصى در بين روستاييان تقويت شود؛ شبكهنهاي اجتماعي حمايت

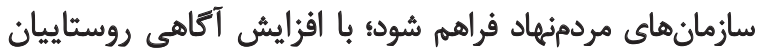

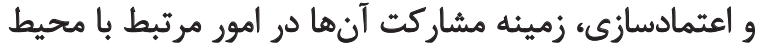

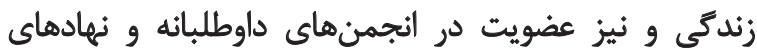

$$
\text { مردمي فراهم شُود. }
$$

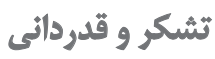

اين مقاله حامى مالى ندارد. از تمامى متخصصان و وناخ

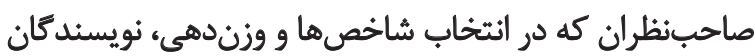
را همراهي كردند تشكر و قدردانى مي كنيهم.
كه در هباني نظرى به آن اشاره شد، همسويى دارد. افْزون

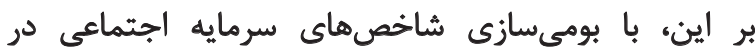

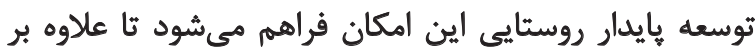
انتخاب شاخصهايى سازكار و منطبق با شرايط روسئ روسثاهاي

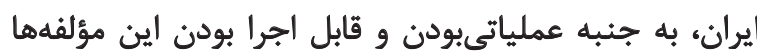

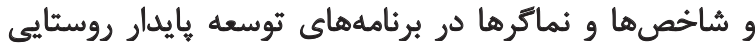

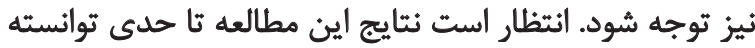

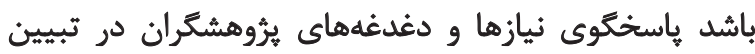

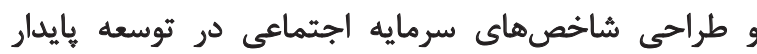
روسيتايى اليران باشد. تشاحص.

يونهن

در يايان يُشنههاد مىشود سرمايه اجتماعى روسثاهاى كشور

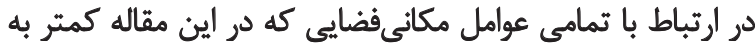

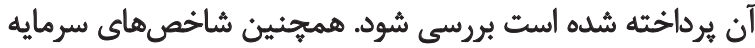

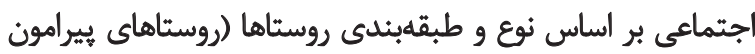

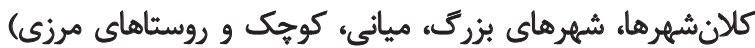

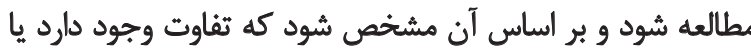

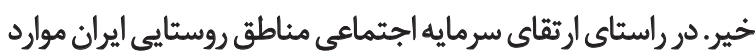

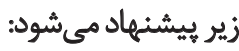




\section{References}

Abrahammson, K. V. (1997). Paradigms of sustainability. In S. Sörlin (ed.), The Road Towards Sustainability, A Historical Perspective, A Sustainable Baltic Region, The Baltic University Programme (pp. 30-5). Sweden: Uppsalla University.

Adibi Sede, M., Yazdkhasti, B., Khorasegani, A. \& Lotfalizade, A. (2009). [Evaluating the social assets among groups (Persian)]. Social Welfare Quarterly, 10(38), 193-220.

Alavizade, A. M. (2004). [Patterns of economical-social development with the focus on rural sustainable development (Persian)] Political \& Economic Ettela'at, (245-246), 190-201.

Amdam, J., \& Amdam, R. (2000). Kommunikativ planleggning: Regional planlegging som reiskap for organisasjons-og samfunnsutvikling. Oslo: Samlaget.

Armstrong, R., Hall, B.J., Doyle, J., \& Waters, E. (2011). Scoping the scope of a Cochrane review. Journal of Public Health, 33(1), 147-150. doi: 10.1093/pubmed/fdr015

Aspen Institute. (1996). Measuring community capacity building: A workbook-in-progress for rural communities. Washington, D.C.: Aspen Institute.

Avijit, G. (1998). Ecology and development in third world (2 ${ }^{\text {nd }} \mathrm{Ed}$.). London: Routledge.

Axinn, G. H., \& Axinn, N. W. (1997). Collaboration in International rural development: A practitioner hand book. London: Sage Publications.

Azarbad, N., Salmani, M., Motiee Langroudi, H. \& Eftekhari, A. (2010). [An analysis on a settlement's network with an emphasis on population flows in Firuzkooh Township (Persian)]. Human Geography Researches, (74), 75-89.

Azkia, M., \& Imani, A. (2008). [Rural sustainable development (Persian)]. Tehran: Etelaate Publication.

Baland, J. M., \& Platteau, J. P. (1996). Halting degradation of natural resources. Is there a role for rural communities?. New York: United Nations.

Binam, J. N., Tonyè, J., wandji, N., Nyambi, G., \& Akoa, M. (2004). Factors affecting the technical efficiency among smallholder farmers in the slash and burn agriculture zone of Cameroon. Food Policy, 29(5), 531-545. doi: 10.1016/j.foodpol.2004.07.013

Bjørnskov, C. (2003). Corruption and social capital [Internet]. Retrieved from pure.au.dk/portal/files/32303928/0003139.pdf

Bjornskov, C., \& Svendsen, G. T. (2003). Measuring social capital- Is there a single underlying explanation? [Internet]. Retrieved from www.hha.dk/nat/wper/03-5_gts.pdf

Brehm, J., \& Rahn, W. (1997). Individual-Level Evidence for the Causes and Consequences of Social Capital. American Journal of Political Science, 41(3), 999. doi: 10.2307/2111684

Brown, T. F. (1998). Theoretical perspectives on social capital, working paper, Program for comparative and international development. Baltimore: John Hopkins University.

Bryant, C., \& Norris, D. (2002). Measurement of social capital: The Canadian experience. Paper presented at The OECD-UKONS International Conference on Social Capital Measurement, 25-27 September 2002, London, UK
Bullen, P., \& Onyx, O. (1998). Measuring social in five communities in NSW: A practitioner's guide. Journal of Applied Behavior, 36(1) 23-42. doi: $10.1177 / 0021886300361002$

Casson, M. C., Della Giusta, M., \& Kambhampati, U. S. (2009). For$\mathrm{mal}$ and informal institutions and development. World Development, 38(2), 137-141. doi: 10.1016/j.worlddev.2009.10.008

Chavez, R., Kemp, L., \& Harris, E. (2004). The Social capital: Health relationship in two disadvantaged neighbourhoods. Journal of Health Services Research E Policy, 9(suppl 2), 29-34. doi: $10.1258 / 1355819042349871$

Chambers, R. \& Conway, G. R. (1991). Sustainable rural livelihoods: practical concepts for the $21^{\text {st }}$ century. Brighton, East Sussex: Institute of development studies.

Chaskin, R. J. (2001). Building community capacity: A definitional framework and case studies from a comprehensive community initiative. Urban Affairs Review, 36(3), 291-323. doi: $10.1177 / 10780870122184876$

Cheers, B., Cock, G., Keele, L. H., Kruger, M., \& Trigg, H. (2005) Measuring community capacity: An electronic audit tool. Paper presented at The $2^{\text {nd }}$ National Conference on the Future of Australia's Country Towns, 11-13 July 2005, Bendigo, Australia

Choi, H. C., \& Sirakaya, E. (2006). Sustainability indicators for managing community tourism. Tourism Management, 27(6), 1274-1289. doi: 10.1016/j.tourman.2005.05.018

Coleman, J. S. (1988). Social capital in the creation of human capital. American Journal of Sociology, 94, 95-120. doi: 10.1086/228943

Cox, D. (1996). Showing the way: Methodologies for successful rural poverty alleviation projects. New York: United Nations.

Cramb, R. A. (2005). Social capital and soil conservation: Evidence from the Philippines. Australian Journal of Agricultural and Resource Economics, 49(2), 211-226. 10.1111/j.1467-8489.2005.00286.x

Daiz, H. L., Drumm, R. D., Ramirez-Johnson, J., \& Oidjarv, H. (2002) Social capital, economic development and food security in Peru's mountain region. International Social Work, 45(4), 481-495. doi: $10.1177 / 00208728020450040601$

Diallo, I. (2005). Language planning, languages-in-education policy and attitudes towards languages in Senegal [PhD thesis]. Queensland: Griffith University.

DFID. (1999). Sustainable livelihoods guidance sheets. London: Department for International Development.

Dobie, P. (2004). Models for national strategies: Building capacity for sustainable development. Development Policy Journal, 1, 1-167

Eftekhari, A. \& Badri, A. (2012). [The theoretical basis of rural developmental patterns, governorship of Guilan (Persian)]. Gilan: Governor of Gilan Pub.

Eftekhari, A., Azimi Amoli, J., Pourtaheri, M., \& Ahmadipour, Z (2011). [Determining the relationship between good governorship and sustainable development in rural areas of Mazandaran (Persian)]. Rural Researches, 2(4), 1-34.

Eftekhari, A., Mahdavi, D., \& Pourtaheri, M. (2010). [The process of Localization of indexes of tourism sustainable development of rural areas in Iran (Persian)]. Rural Researches, 1(4), 1-41.

Firouzjaie, A. A., Sadighi, H., \& Mohammadi, M. A. (2007). The influence of social capital on adoption of rural development 
programs by farmers in the Caspian Sea Region of Iran. American Journal of Agricultural and Biological Sciences, 2(1), 15-22. doi: 10.3844/ajabssp.2007.15.22

Falk, I., \& Kilpatrick, S. (2000). What is social capital? A study of interaction in a rural community. Sociologia Ruralis, 40(1), 87-110. doi: 10.1111/1467-9523.00133

Farahani, H., Abdi, S. \& Cheraghi, M. (2012). [Evaluation of social asset's influence in development of rural areas with the focus of life quality (Case study: Mashhad District, Mighan, Arak county) (Persian)]. Regional Planning, 2(8), 67-78.

Fathi, S. (2012). [An analysis of the role of social assets of rural developments (Persian)]. Quartery of Geography (Regional Planning), 2(2), 195-214

Fernandez, R., Castilla, E., \& Moore, P. (2000). Social capital at work: Networks and employment at a phone center. American Journal of Sociology, 105(5), 1288-1356. doi: 10.1086/210432

Fine, B. \& Green, F. (2000). Economics, social capital, and the colonization of the social sciences. In S. Baron, J. \& T. S., Field (Ed.), Social Capital, Critical Perspectives (pp. 78-93). Oxford: Oxford University Press.

Flora, C., Kinsley, M., Luther, V., Wall, M., Odell, S., Ratner, S. et al. (1999). Measuring community success and sustainability: An interactive workbook. Iowa: Iowa State University Press.

Fokoyama, F. (1995). The social virtues and the creation of prosperity. New York: Colombia University Press.

Foster-Fishman, P. G., Berkowitz, S. L., Lounsbury, D. W., Jacobson, S., \& Allen, N. A. (2001). Building collaborative capacity in community coalitions: A review and integrative framework. American Journal of Community Psychology, 29(2), 241-261. doi:10.1023/a:1010378613583

Goodman, R. M., Speers, M. A., Mcleroy, K., Fawcett, S., Kegler, M., Parker, E., et al. (1998). Identifying and defining the dimensions of community capacity to provide a basis for measurement. Health Education \& Behavior, 25(3), 258-278. doi:10.1177/109019819802500303

Grootaert, C. (1999). Social capital, household welfare and poverty in Indonesia; Working Paper No. 6. Washington, D.C.: World Bank.

Grootaert, C., \& Narayan, D. (2000). Local institutions, poverty, and household welfare in Bolivia; Working Paper No. 9. Washington, D.C.: World Bank.

Grootaert, C., \& Bastelaer, T. (2002). The role of social capital in development. Cambridge: Cambridge University Press.

Harper, R. (2002). The measurement of Social Capital in the United Kingdom. Oxford: Office for National Statistics.

Healey, P. (1997). Collaborative planning. Shaping places in fragmented societies. London: Macmillan Press Ltd.

Healey, P., Madanapour, A. \& Magalhaes, C. (1999). Institutional capasity-building, urban planning and urban regeneration projects. In M. Sotarauta (Ed.), Urban Futures: A Loss of Shadows in the Flowing Spaces? (pp. 117-137). Austin: Futura Publishing LLC.

Healy, T. (2002). The measurement of social capital at international level [Internet]. Retrieved from www.oecd.org/innovation/research/2380281.pdf
Hjollund, L., \& Svendsen, G. T. (2000). Social capital: A standard method of measurement [Internet]. Retrieved from www.hha.dk/nat/ wper/00-9_gts.pdf

Homans, G. (1961). Social behavior: Its elementary forms. New York: Harcourt, Brace and World.

Inglehart, R. (1997). Modernization and postmodernization: Cultural, economic and political change in forty three societies. New Jersey: Princeton University Press.

Innes, J. E., \& Booher, D. E. (2003). The impact of collaborative planning on governance capacity. Berkeley: Institute of Urban and Regional Development.

Isham, J. (1999). The effect of social capital on technology adoption: Evidence from rural Tanzania. IRIS working paper No. 235. Retrieved from SSRN: https:// ssrn.com/abstract=260053 or http:/ /dx.doi. org/10.2139/ssrn.260053

Jacobs, J. (1961). The life and death of great American cities. New York: Penguin Random House.

Kawachi, I., Lochner, A., \& Kennedy, B. P. (1997). Long live community: Social capital as public health [Internet]. Retrieved from http:/ / prospect.org/article/long-live-community

Kawachi, I., Bruce, K., \& Glass, R. (1999). Social Capital and self-rated health: A contextual analysis. American Journal of Public Health, 89(8), 1187-1193. doi: 10.2105/ajph.89.8.1187

Khani, F., Ghadiri Maasoum, M. \& Molkan, A. (2013). The influence of social assets on improvement of rural development (Case study: Godin District, Kangavar County), (Persian)]. Geography, 11(38), 133-152.

Knack, S. (2002). Social capital and the quality of government: Evidence from the states. American Journal of Political Science, 46(4) 772. doi: $10.2307 / 3088433$

Krishna, A. (2004). Understanding, measuring and utilizing social capital: Clarifying concepts and presenting a field application from India. Agricultural Systems, 82(3), 291-305. doi: 10.1016/j. agsy.2004.07.003

Krishna, A. \& Shrader, E. (1999). Social capital assessment tool. Paper presented at The Conference on Social Capital and Poverty Reduction, $22-24$ June 1999, Washington, USA.

Krishna, A. \& Uphoff, N. (1999). Mapping and measuring social capital: A conceptual and empirical study of collective action for conserving and developing watersheds in Rajasthan, India. Washington, D.C.: World Bank.

La Porta, R., Lopez-de-Silanes, F., Shleifer, A., \& Vishny, R. W. (1998) Law and finance. Journal of Political Economy, 106(6), 1113-1155. doi: $10.1086 / 250042$.

Lehtonen, M. (2004). The environmental-social interface of sustainable development: Capabilities, social capital, institutions. Ecological Economics, 49(2), 199-214. doi: 10.1016/j.ecolecon.2004.03.019

Lin, N. (1999). Building a network theory of social capital. Connections, 22(1), 28-51.

Lin, N. (2000). Inequality in social capital. Contemporary Sociology, 29(6), 785-795. doi: $10.2307 / 2654086$

Lin, N. (2001). Social capital: A theory of social structure and action. Cambridge: Cambridge University Press. 
Loury, G. (1992). The economics of discrimination: Getting to the core of the problem. Harvard Journal for African American Public Policy, I: 91-110.

Lusthaus, C. (1995). Institutional assessment: A framework for strengthening organizational capacity for IDRC's Research Partners. Ottawa: International Development Research Centre.

Maclellan-Wright, M. F., Anderson, D., Barber, S., Smith, N., Cantin, B., Felix, R., \& Raine, K. (2007). The development of measures of community capacity for community-based funding programs in Canada. Health Promotion International, 22(4), 299-306. doi: 10.1093/heapro/dam024

Magnani, N., \& Struffi, L. (2009). Translation sociology and social capital in rural development initiatives. A case study from the Italian Alps. Journal of Rural Studies, 25(2), 231-238. doi: 10.1016/j. jrurstud.2008.10.004

Merino, S. S., \& Carmenado, I., \& de Los R. (2012). Capacity building in development projects. Procedia - Social and Behavioral Sciences, 46, 960-967. doi: 10.1016/j.sbspro.2012.05.231

Minten, B., \& Fafchamps, M. (1999). Social capital and the firm: Evidence from agricultural trade. Washington, D.C.: World Bank.

Martin, K. S., Rogers, B. L., Cook, J. T., \& Joseph, H. M. (2004). Social capital is associated with decreased risk of hunger. Social Science $\mathcal{E}$ Medicine, 58(12), 2645-2654. doi: 10.1016/j.socscimed.2003.09.026

Mohan, J., Twigg, L., Barnard, S. \& Jones, k. (2005). Social capital, geography and Health: A Small area analysis for England. Social Science and Medicine, 60(6), 1267-1283. doi: 10.1016/j.socscimed.2004.06.050

Nahapiet, J., \& Ghoshal, S. (1998). Social capital, intellectual capital, and the organizational advantage. Academy of Management Review, 23(2), 242-266. doi: 10.5465/amr.1998.533225

Narayan, D., \& Pritchett, L. (1999). Cents and sociability: Household income and social capital in rural Tanzania. Economic Development and Cultural Change, 47(4), 871-897. doi: 10.1086/452436

Narayan, D., \& Cassidy, M. F. (2001). A Dimensional dimensional approach to measuring social capital: Development and validation of a social capital inventory. Current Sociology, 49(2), 59-102. doi:10.1177/0011392101049002006

Norris, D. (2005). Social Capital Measurement: National Experiences and International Harmonization- A Beginning. Paper presented at The Siena Group Meeting, 2005 February 2, Helsinki, Finland.

North, D. (1990). Institutions, institutional change, and economic performance. Cambridge: Cambridge University Press.

Offe, C., Fuchs, S. (2002). A decline of social capital? The German case. Chapter In Putnam, R. D., (ED.). Democracies in Flux (pp. 189244), Putnam, R. Oxford: Oxford University Press.

Paldam, M. (2001). Social capital: One or many? Definition and measurement. Journal of Economic Surveys, 14(5), 629-653. doi: 10.1111/1467-6419.00127

Pennar, K. (1997). The ties that lead to prosperity: The economic value of social bonds is only beginning to be measured. Business Week, 153-155.

Platteau, J. P. (1994). Behind the market stage where real societies exist-Part I: the role of public and private order institutions. Journal of Development Studies, 30(3), 533-577. doi $10.1080 / 00220389408422328$
Portes, A. (1998). Social capital: its origins and application in modern sociology. In Lesser, E., (Ed.). Knowledge and Social Capital. Philadelphia: Elsevier.

Putnam, R. (1993). Making democracy work: Civic traditions in modern Italy. Princeton, N. J.: Princeton University Press.

Putnam, R. D. (1995). Tuning in, tuning out: the strange disappearance of social capital in America. Political Science \& Politics, 28(4), 664-683. doi: 10.1017/s1049096500058856

Putnam, R. (2000). Bowling alone: The collapse and revival of American community. New York: Simon and Schuster.

Reid, C., \& Salmen, L. (2002). Understanding social capital. Agricultural extension in Mali: Trust and social cohesion. Social capital initiative working paper No. 22. Washington, D.C.: World Bank.

Rezvani, M. (2002). [Schedule of rural development (the concepts, guidelines and processes) (Persian)]. Journal of Tehran University Faculty of Literature and Humanities, 52(164), 221-240.

Sabatini, F. (2005). Resources for the study of social capital. The Journal of Economic Education, 36(2), 198-198. doi: 10.3200/ jece.36.2.198-198.

Sakata, S. (2002). [What is social capital? (Japanese)]. Tokyo: Japan International Cooperation Agency.

Sarafi, M. (1996). [The basis of regional planning (Persian)]. Tehran: Organization of Planning and Budget Publication.

Schafft, K. A., \& Brown, D. L. (2000). Social capital and grassroots development: The case of Roma self-governance in Hungary. Social Problems, 47(2), 201-219. doi: 10.1525/sp.2000.47.2.03×0288b

Schoeffel, P., Overton, J., \& Scheyvans, R. (2000). Strategies for sustainable development: Experiences from the pacific. Pacific Affairs, 73(3), 475. doi: $10.2307 / 2672065$

Schwarz, A. M., Béné, C., Bennett, G., Boso, D., Hilly, Z., Paul, C., et al. (2011). Vulnerability and resilience of remote rural communities to shocks and global changes: Empirical analysis from Solomon Islands. Global Environmental Change, 21(3), 1128-1140. doi: 10.1016/j.gloenvcha.2011.04.011.

Seeley, J. R., Alexander Sim, R., Loosley, E. W., \& Riesman, D. (1956) Crestwood heights: A study of the culture of suburban life. New York: Basic Books.

Serageldin, I. \& Grootaert, C. (2000). Defining social capital: An integrating view. Washington: World Bank.

Small, M. L. (2002). Culture, cohorts, and social organization theory: understanding local participation in a Latino housing project. American Journal of Sociology, 108(1), 1-54. doi: 10.1086/345649

Stone, W. (2001). Measuring Social Capital: Towards a Theoretically informed measurement framework for researching social capital in family and community life. Melbourne: Australian Institute of Family Studies.

Svendsen, G. L. H., \& Svendsen, G. T. (2000). Measuring social capital: The Danish co-operative dairy movement. Sociologia Ruralis, 40(1), 72-86. doi: 10.1111/1467-9523.00132

Szajnowska-Wysocka, A. (2009). Theories of regional and local development - abridged review. Bulletin of Geography. Socio-Economic Series, 12(12). doi: 10.2478/v10089-009-0005-2 
Tajbakhsh, K. (2005). [Social asset: Confidence, democracy and development (Persian)]. Tehran: Shirazeh.

Uslaner, E. M. (2001). Trust and corruption. Paper presented at The Conference on Political Scandals, Past and Present, England, Salford, 21-23 June 2001.

Kwan, B., Frankish, J., Quantz, D., \& Flores, J. (2003). A synthesis paper on the conceptualization and measurement of community capacity. Vancouver, British Columbia: Institute of Health Promotion Research.

World Commission on Environment and Development (WCED). (1987). From one earth to one world: An overview. Oxford: Oxford University Press.

World Resources Institute, United Nations, World Bank. (2008). World resources 2008: Roots of resilience growing the weal th of the poor. Washington, D.C.: World Resources Institute.

Whiteley, P. F. (2000). Economic growth and social capital, Political Studies, 8, 443-466. doi: 10.1111/1467-9248.00269

Woolcock, M. (2001). The place of social capital in understanding social and economic outcomes [Internet]. Retrieved from https://www. google.com/url?sa $=t \& r c t=j \& q=\& e s r c=s \&$ source $=w e b \& c d=1 \& c a$ $\mathrm{d}=$ rja\&uact $=8 \&$ ved $=0$ ahUKEwiuy $9 \mathrm{vXz}$ PPSAhVpJsAKHU7zBfY QFggZMAA\&url=http\%3A\%2F\%2Fwww.oecd.org\%2Finnovati on\%2Fresearch\%2F1824913.pdf\&usg=AFQjCNFEkrcfxIKJhke2Z 0GUbveELZMomA\&sig2=6xOMRiUMoM3R75etf82i9Q\&bvm= bv.149397726,d.ZGg

Wu, B., \& Pretty, J. (2004). Social connectedness in marginal rural China: The case of farmer innovation circles in Zhidan, North Shaanxi. Agriculture and Human Values, 21(1), 81-92. doi: 10.1023/bahum.0000014025.47576.72

Yokoyama, S. \& Ishida, A. (2006). Social capital and community development: a review from: Potential of social capital for community development. Tokyo: Asian Productivity Organization.

Zahedi Mazandarani, M. J. (2005). [The saving power of rural families and its effects on rural cooperation on development process (Persian)]. Agricultural Economics and Development, 13(49), 27-62.

Zak, P. J., \& Knack, S. (2001). Trust and growth. The Economic Journal, 111, 295-321. doi: 10.1111/1468-0297.00609

Zucker, L. G. (1986). Production of trust: institutional sources of economic structure, 1840-1920. Research in Organizational Behavior, 8, 53-111. 
